\title{
Triclosan Induced Oxidative Stress, Estrogenicity, Mutagenicity, Carcinogenicity, and Genotoxicity: A Novel Therapeutic Approach
}

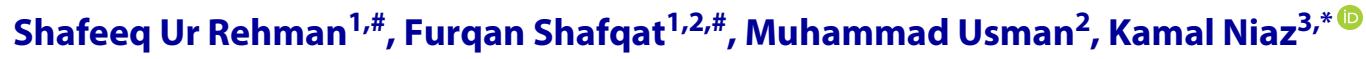

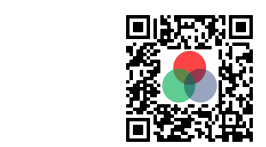

Use your smartphone to scan this QR code and download this article

${ }^{\#}$ Authors contributed equally

${ }^{1}$ Department of Microbiology, Faculty of Veterinary Science, Cholistan University of Veterinary \& Animal Sciences, Bahawalpur-63100, Pakistan

${ }^{2}$ Department of Anatomy \& Histology, Faculty of Bio-Sciences, Cholistan University of Veterinary \& Animal Sciences, Bahawalpur-63100, Pakistan

${ }^{3}$ Department of Pharmacology \& Toxicology, Faculty of Bio-Sciences, Cholistan University of Veterinary \& Animal Sciences, Bahawalpur-63100, Pakistan

\section{Correspondence}

Kamal Niaz, Department of Pharmacology \& Toxicology, Faculty of Bio-Sciences, Cholistan University of Veterinary \& Animal Sciences, Bahawalpur-63100, Pakistan

Email: kamalniaz@cuvas.edu.pk

History

- Received: Oct 06, 2021

- Accepted: Dec 03, 2021

- Published: Dec 30, 2021

DOI : 10.15419/bmrat.v8i12.712

\section{Check for updates}

\section{Copyright}

(c) Biomedpress. This is an openaccess article distributed under the terms of the Creative Commons Attribution 4.0 International license.

\begin{abstract}
Triclosan (TCS) is present in toothpaste and other cosmetic products as an antibacterial and antifungal agent. This manuscript highlights that TCS is a potential oxidative stress-causing agent, an estrogenic, mutagenic, cancer-causing agent, and genotoxic agent present in cosmetic products. This study also summarizes the therapeutic approach to overcome all of the harmful effects. It is a popular current topic, and a new research study is needed to find a new alternative as an antibacterial and anti-fungal agent instead of TCS. TCS causes oxidative stress when the dynamic balance in synthesizing and removing reactive oxygen species (ROS) within typical physiological circumstances is disturbed. The antioxidant defence system includes both enzymatic and non-enzymatic antioxidants produced by the organism to tackle the harmful effects of ROS. TCSs have estrogenic, proliferative, and apoptotic properties due to research on cell fate. The mutagenic potential of TCS has been examined using in vitro and in vivo research in prokaryotic, eukaryotic systems, and mammalian cells. It also induces carcinogenic, estrogenic, and mutagenic effects. TCS's therapeutic effects, especially against inflammatory skin conditions, have been demonstrated by many materials gathered from in vitro and in vivo experiments. The new findings suggest that TCS, a commonly used cosmetic product, may cause cancer, as shown by animal and human models and clinical trials. TCS is not effectively regulated, as evidenced by its presence in various environmental media, human bodies, and animals. Its irresponsible usage and disposal may endanger humans and wildlife. TCS has been found to damage a wide variety of cells in cell-based investigations. TCS's exact function in the environmental selection of antibiotic and multidrug resistance genes is still unclear. Comprehensive evaluations of these domains, especially to derive serious human health risk inferences from TCS outcomes, may help future research and legislation to better serve the public's health.

Key words: Antibacterial, Anti-fungal, Cosmetic, Estrogen, Genetic, Oxidative Stress, Toxicity, Triclosan, Tumor
\end{abstract}

\section{INTRODUCTION}

Toothpaste is the most widely used cosmetic product for teeth protection in modern societies. There are many chemicals and natural products that act as an antibacterial, antifungal, and protectant for teeth. However, its constituents include Triclosan (TCS), an antibacterial and antifungal agent to protect teeth from deleterious effects. TCS is also used in other cosmetic products such as soaps, detergents, toys, and surgical cleaning treatments ${ }^{\mathbf{1}, 2}$. TCS is widely regarded as a broad-spectrum biocide that targets bacterial membranes, and cellular resistance is uncommon if TCS has a unique mechanism of action. Since the TCS inhibits Escherichia coli (E. coli) enoyl reductase $(F a b I)$, the bisphenol has also been found to inhibit the enzyme from different bacteria such as Pseudomonas aeruginosa (P. aeruginosa) and Staphylococcus aureus (S. aureus). TCS's inhibitory action on enoyl reductase was discovered, FabK in P. aerug- inosa and Staphylococcus pneumoniae (S. pneumoniae), fabL in Bacillus subtilis (B. subtilis), InhA in Mycobacterium smegmatis (M. smegmatis), and Mycobacterium tuberculosis (M. tuberculosis) have all been identified ${ }^{3,4}$. FabK and FabL are TCS resistant, whereas InhA is not. Similar inhibition of TCS fatty acid production was seen in higher lifeforms, including Plasmodium falciparum P. falciparum), which causes malaria, and Toxoplasma gondii (T. gondii) ${ }^{3,5}$. TCS is easily photodegraded in the environment, despite its high chemical volatility and resistance to high and low $\mathrm{pH}$. In the laboratory, they found eight photochemical by-products. Under various irradiation wavelengths, Latch et al., ${ }^{6}$ reported TCS photoconversion to 2,8-dichlorodibenzo-p-dioxin (2,8-DCDD) with up to $12 \%$ output at $\mathrm{pH}>8$. The yield of 2,8 DCDD under laboratory settings (pure water) and river water treated with TCS was compared ${ }^{7}$. According to findings comparable to lab and field settings, TCS can be converted to 2,8-DCDD in sunlight 
irradiated water sources. According to Son et al., ${ }^{\mathbf{8}}$, radicals that enhance transitional dioxin degradation control TCS breakdown by titanium dioxide photocatalysis. Oxidative damage to lipid membrane, protein, and nucleic acid may result from insufficient reactive oxygen species (ROS) scavenging ${ }^{9}$. Reduced glutathione (GSH), catalase (CAT), glutathione peroxidase (GPx), superoxide dismutase (SOD), and glutathione reductase (GR) are examples of enzymatic and non-enzymatic antioxidants that defend against the harmful consequences of ROS. The peroxidation of cell membrane lipids may occur when organisms are exposed to ROS-producing contaminants. Malondialdehyde (MDA) is a biomarker for assessing cell membrane destruction that is produced as a result of membrane lipid peroxidation (LPO) ${ }^{10}$. After subchronic TCS treatment, the antioxidant mechanism of the liver may be unable to remove ROS produced by TCS, which might explain the elevated MDA levels. Antioxidant compounds are free radical scavengers because they prevent or delay-free the radical oxidation of substrates, resulting in significant LPO protection in biological systems ${ }^{11}$. Phenolic and polyphenolic chemicals are the most common natural antioxidants found in plants, foods, and beverages. The total antioxidant capacity (TAC) was calculated by reducing Mo (VI) to Mo (V) in the extract and forming a green phosphate/Mo(V) complex at an acid $\mathrm{pH}^{\mathbf{1 2}}$. It evaluates overall antioxidant capacity, including both water and fat-soluble antioxidants. It has been suggested that electron donation is related to antioxidant activity, which indicates a decrease in bioactive chemical potency. Antioxidants may operate as reductants, and the deactivation of oxidants by reductants can be thought of as redox reactions in which one reaction species is reduced while the other is oxidized. Antioxidants have been found in the root of Anchomanes difformis (A. difformis), which may play a role in the plant's medicinal action ${ }^{\mathbf{9}, \mathbf{1 3}}$. On the other hand, TCS interacts with Agrobacterium tumefaciens (A. tumefaciens) AcrR, causing structural changes and inhibiting adhesion to the AcrA promoter. TCS membrane association in human erythrocytes was also studied to see the underlying mechanisms of electrolytes channels. TCS induced $\mathrm{K}^{+}$outflow and haemolysis, implying membrane breakdown while preventing hypotonic lysis, which might be mediated by membrane enlargement. TCS significantly decreased the enzymatic efficiency of membrane-bound $\mathrm{K}^{+}, \mathrm{Na}^{+}$, $\mathrm{Mg}^{2+}$-ATPase ${ }^{14}$. TCS affects erythrocyte osmoregulation, promotes membrane instability, and inhibits monovalent ion movement. According to studies on its impact on cell fate, TCS possesses estrogenic, proliferative, and apoptotic characteristics ${ }^{14}$. The cell cycle and death genes and proteins are especially susceptible to TCS regulation. TCS is cytotoxic to epithelial cells and gingival fibroblasts, suggesting that this may be a new apoptosis inducer in these cells. A research team used BG-1 ovarian cancer cells in various in vivo and in vitro studies to see how TCS affected the growth and proliferation of these cells. TCS promotes cell proliferation and raises the protein levels and expression of the cyclin D1 gene while decreasing the expression and protein levels of the p21 and Bax genes. After exposure to TCS, inflammation started via Toll-like receptor-4 (TLR-4)-mediated signalling mechanism through gut microbiota. Mustafa et al., ${ }^{14}$ discovered TCS targets in human gingival fibroblasts, including interleukin- $\beta$ (IL- $1 \beta$ ), interferon- $\gamma$ (IFN$\gamma$ ), prostaglandin E synthase-1 (PGES-1), and major histocompatibility complex class II (MHC-II). Investigations into the subcellular localization of TCS have shown that nucleus accumulation takes priority over cytosolic accumulation ${ }^{\mathbf{1 4}}$. Due to the greater initial absorption of cytoplasmic TCS, a substantial portion of cytosolic TCS was removed after each wash, whereas nuclear TCS was retained. This may explain why TCS has different inflammatory signals. However, it has been known to be a potential endocrine disruptor due to binding to androgen and oestrogen receptors ${ }^{15-17}$. In terms of TCS's androgenic properties, it was found that TCS inhibits testosteronedependent transcription while increasing androgendependent transcription. TCS stimulates or inhibits a variety of signaling pathways, according to evidence on xenobiotic responses to TCS ${ }^{18}$. Although considerable progress has been made in TCS signaling, much remains unknown regarding TCS's modulatory effects on cellular physiology, especially in human-based systems. In the administration to the whole blood leukocytes, TCS inhibited TLR signaling. It leads to the downregulation of several signaling mediators, most notably NF-B inducing kinase (Nik) and C-jun. It explains the cells' cumulative lowered inflammatory response lipopolysaccharides (LPS). TCS's endocrine-disrupting properties, particularly its estrogenicity, has grabbed researchers' attention. TCS promoted proliferation in BG-1 ovarian cancer cells through the oestrogen-receptor (ER), as shown by Kim J-Y et al. ${ }^{19}$. TCS's mutagenic potential has been studied in prokaryotic and eukaryotic systems using in vitro and in vivo investigations. It looks for frame shift mutations, point mutations, clastogenic events, and recombination events ${ }^{20}$. 
TCS did not induce gene mutations within these systems, as shown by the negative findings of these reverse mutation studies in vitro and the host. In vitro studies of gene mutations of mammalian cells in mouse lymphoma, L5178Y cells with and without metabolic stimulation show that the potential for TCS to induce mutations in the thymidine kinase (TK) domain was examined ${ }^{21}$. Studies have proven that TCS exhibits anti-androgenic and anti-estrogenic properties, depending on species, tissues, and cell types ${ }^{22}$. A study in China had shown that prenatal TCS exposure in pregnant women led to higher cord testosterone levels in infants ${ }^{23}$. Another study revealed that TCS was higher in urine samples than $75 \%$ in all tested samples ${ }^{\mathbf{2 4}}$. Here, we summarized findings from recent studies, which suggest tumorigenic effects of TCS. It has been reported in many studies that extensive usage of TCS can have cancerogenic potential. Recently, TCS has been demonstrated to cause colonassociated inflammation, which ultimately leads to colitis-mediated colon tumours. TCS is also associated with higher colitis symptoms, ultimately leading to colitis-mediated colon cancer ${ }^{25}$.

TCS's effects on breast cancer cells in vitro may be influenced by the concentration and other factors such as oestradiol (natural oestrogen). A smaller head circumference at birth, early breast development, antibiotic resistance, and hypersensitivity are all possible health consequences. TCS's presence in milk suggests that it has travelled through the human breast, raising concerns about its involvement in breast cancer development. A commonly used antimicrobial preservative in personal care products, TCS is an endocrine disruptor in hormone-dependent tissues. TCS increases vascular endothelial growth factor (VEGF) production, a chemical that promotes tumour growth via human prostate cancer stromal cells ${ }^{26}$. TCS's first specific action method in prokaryotic cells was identified just 20 years ago when it was revealed that TCS suppressed fatty acid synthesis (FAS) in E. coli ${ }^{27}$. By replicating its native substrate in vivo, TCS permanently blocked the FAS enzyme enoyl-acyl carrier protein (Enoyl-ACP) reductase ${ }^{28}$. TCS resistance was also shown by a mutant or overexpressed ACP expressed by $f a b I$ in bacteria.

As a consequence of these investigations, ACP was identified as an intracellular TCS target. Multiple studies supporting fatty acid formulation suppression as a novel strategy for chemotherapy have been inspired by the effectiveness of cerulenin, a mycotoxin that inhibits FAS in vivo. FAS appears and acts differently in normal and malignant tissues, with the latter having a higher therapeutic index ${ }^{28}$. Because of its long history of human usage and broad prevalence in consumer products, as well as promising in vivo results, TCS is a suitable choice for chemotherapy. TCS may enhance the proliferation of BG-1 ovarian cancer cells by modulating the expression of cell cycle and cell death genes via ER-based mechanisms, according to in vitro research ${ }^{29}$. TCS, like E2, was shown to have estrogenic properties via altering the appearance of protein kinase $\mathrm{B}$ (PKB), mitogenactivated protein kinase (MAPK), phosphorylated insulin receptor substrate-1 (pIRS-1), and extracellular signal-regulated kinase (ERK) proteins ${ }^{30}$. It also inhibited the protein synthesis of pIRS-1, PKB, MAPK, and ERK, which were all increased by E2 or TCS, and therefore had an antiestrogenic effect. As shown through its prevalence in various environmental media, human bodies, and animals, TCS is not effectively regulated. Its careless use and disposal may put people and the environment at risk. In cell-based studies, TCS is harmful to many cells ${ }^{\mathbf{1 4}}$. The precise role of TCS in selecting antibiotic resistance genes and multidrug resistance genes in the environment is unknown. It is also necessary to establish the TCS level required for tolerance choice in environmental communities. Future research should concentrate on finding signaling molecules controlled by TCS in different ways and determining their involvement in harmful or protective effects in various cell types ${ }^{\mathbf{1 4}}$.

TCS has been shown to reduce the viability and growth of Michigan Cancer Foundation-7 (MCF-7) and $\mathrm{SKBr}-3$ cells in culture at a range of $2.5-20 \mu \mathrm{g} / \mathrm{mL}$. It also lessened the binding affinity of inhibitors in human and goose type-1 fatty acids as well as the enoylreductase level ${ }^{31-33}$. All present new reports indicate that widely used TCS cosmetic agents can trigger cancer, as shown in animal and human models ${ }^{\mathbf{2 1 , 3 4 - 3 6}}$ as well as in clinical studies. Therefore, government policies should reassess TCS usage in cosmetic products to prevent its harmful effects on human health. This manuscript's main aim is to highlight that TCS causes oxidative stress, an estrogenic, mutagenic, cancercausing agent, and genotoxic agent present in cosmetic products. A further aim is to attenuate the TCS toxicity via natural products.

\section{BIOSYNTHESIS OF TCS}

TCS is a broad-spectrum antibiotic that inhibits bacterial fatty acid biosynthesis at the (Enoyl-ACP) reductase $^{37}$. TCS is generally considered a broad biocide that targets bacterial membranes, and cellular resistance is rare if TCS does not have a distinct mode of action. TCS has been found to inhibit enoyl reductase FabI in various bacteria, including $P$. aeruginosa 
and $S$. aureus, after discovering that it blocks the enzyme in . coli $^{38}$. The enoyl-ACP reductase FabI family produces noncovalent, high-affinity ternary compounds with TCS and NAD $(\mathrm{P})^{+}$that effectively limit the enzyme's participation in biosynthesis ${ }^{39}$. TCS inhibits enoyl reductase by attaching to a location close to the nucleoside cofactor's nicotinamide ring. The TCS phenol ring interacts with the nicotinamide ring directly and enables substantial activities ${ }^{\mathbf{4 0}}$.

More enoyl reductase genes have been identified after discovering TCS's inhibitory effect on enoyl reductase, including FabK in S. pneumoniae and P. aeruginosa, FabL in B. subtilis InhA in M. tuberculosis, and M. smegmatis ${ }^{41}$. Both FabK and FabL are TCS resistant, whereas $\operatorname{Inh} A$ is sensitive. Similar inhibition of TCS fatty acid biosynthesis was also observed in higher life forms, such as P. falciparum and T. gondii, which cause malaria ${ }^{42}$. Both of these species have a type II fatty acid synthase since they are apicomplexans. TCS was recently demonstrated to block a type I fatty acid synthase (a versatile human enzyme) in breast cancer cells, even though these enzymes are commonly thought to be antibiotic-resistant ${ }^{43}$.

\section{DEGRADATION OF TCS}

Antimicrobial compounds have shown a proclivity for bioaccumulation in underwater organisms, and they have been found to survive in aquatic environments for longer periods. The presence of TCS in the environment necessitates the monitoring of surface water. TCS was discovered in silt from Greifensee Lake in Switzerland deposited 30 years ago ${ }^{44}$. The survivability of TCS in sediment was confirmed in this investigation, and a breakdown of the TCS using various strategies. The TCS level in sediment has progressively enlarged since the early 1960 s, when it was initially introduced, to the mid-1970s, indicating that its usage trends were becoming more widespread. This trend reversed from the mid-1970s to the early 1980s, with most wastewater treatment facilities introducing a different conventional treatment stage. TCS levels have risen since the early 1980s, owing to its rising popularity and use ${ }^{44}$.

Nonetheless, the comparatively large level of TCS found in a 30-year-old sedimentary layer from 1970 to 1971 indicated that TCS breakdown was highly sluggish in the sediment ${ }^{45}$. A parallel timeline pattern for TCS in estuary sediments in the United States was also documented. Antimicrobial chemicals can subdivide into sediments and withstand breakdown mechanisms under anaerobic circumstances, as evidenced by TCS's environmental survival in sediments. Furthermore, sediments are the last sink for the aqueous ecosystem. TCS persistence in this medium would be risky since bioturbation generated by animals or human excavation might push it back into the aqueous ecosystem ${ }^{\mathbf{4 6}}$.

Despite its strong chemical volatility and resilience to both high and low $\mathrm{pH}$, TCS has been discovered to be easily destroyed in the atmosphere due to photodegradation. Scientists found eight photochemical pathway subproducts in laboratory testing ${ }^{47}$. Researchers found TCS photoconversion to 2,8-DCDD with an output of up to $12 \%$ at $\mathrm{pH}>8$, using varied illumination intensities. Under the laboratory conditions (purified water), the production of 2,8-DCDD yield was compared to river water spiked with TCS. According to similar results across laboratory and real-world scenarios, TCS could transform into 2,8-DCDD in sunshine irradiated water sources ${ }^{48}$. TCS that persists in the secondary discharge after sediment processing may be chemically transformed after disposal. In the United States, sodium hypochlorite, a sterilizing oxidant and a producer of free chlorine is extensively used for various applications and may interact with TCS. In certain instances, the TCS phenol carbons may be chlorinated in either ortho- or parapositions, yielding three chlorinated TCS derivative (CTD) transitional compounds ${ }^{49}$. Direct photolysis is ineffective at degrading dioxin derivatives of TCS, so they are therefore not a public health problem ${ }^{6}$. Similarly, chloramination of TCS results in CTDs comparable to those formed by the free method ${ }^{\mathbf{5 0}}$. Chlorinated TCS derivatives like 4-Cl-TCS, 6-ClTCS, and 4,6-Cl-TCS have been found in sewage discharge ${ }^{51}$. CTDs have been discovered at the apex of marine biological chains and as biomethylated equivalents in fresh water, specimens taken downstream of a sewage discharge, and in carps that live in it due to the spread TCS-containing effluents in streams ${ }^{52}$. According to these findings, CTDs are either generated via TCS during water purification using free chlorine or are synthesized without passing through the conventional treatment processes. As a result, CTDs are regarded as a significant environmental concern since they have the potential to preserve or perhaps enhance the antibacterial and endocrine-disrupting properties of TCS. Furthermore, under spontaneous photochemical circumstances, CTDs such as 6-Cl-TCS, 4,6-Cl-TCS, and 4-Cl-TCS have been shown to release dioxins in water ${ }^{53}$.

Buth JM et al., ${ }^{\mathbf{5 4}}$ investigated the history of TCS dioxin photoproducts and their chlorinated counterparts in Mississippi River sedimentary basins. Sunlight irradiation of CTDs, which produces chlori- 
nated dioxins, is another conceivable cause of TCSderived pollutants. The photochemical breakdown of TCS occurs until by-products are subjected to ultraviolet rays after interaction with chlorinated water, 2,4-dichlorophenol (2,4-DCP), and 2,8-DCDD are formed. The chlorination of 2,4-DCP yields 2,4,6-trichlorophenol ${ }^{55}$. The transitional chlorophenols are then converted to chloroform and trihalomethanes ${ }^{56}$. The ways by which CTDs are converted to chlorophenols, chloroform, and trihalomethanes. TCS can be chlorinated by frequent exposure to chlorine at water treatment plants. A wastewater treatment plant discharges chlorinated TCS, which can be converted into more harmful dioxins by sunlight ${ }^{57}$. 2,4-DCP is a contaminant of concern according to the United States environmental protection agency and is hazardous to fish and other aquatic life ${ }^{58} \cdot 2,4-D C P$ is a chemical that is used to make insecticides, disinfectants, and antiseptics.

Furthermore, upon exposure to the sun's rays, the 2,4-DCP decomposes even more, perhaps resulting in more strongly chlorinated dioxins ${ }^{59}$. Due to low levels of ROS in natural rivers and the ineffectiveness of straight photolysis of TCS, research by Latch et al., ${ }^{6}$ found that dioxin chemicals produced from TCS are not a public health risk. Microorganisms like Burkholderia, Pseudomonas, and Sphingomonas may degrade chlorine and $\mathrm{CO}_{2}$ under natural circumstances ${ }^{\mathbf{6 0}}$.

According to Son et al. (2009) ${ }^{\mathbf{6 1}}$, radicals that stimulate the destruction of transitional dioxins control TCS degradation by titanium dioxide photocatalysis. Furthermore, hydrogen peroxide enhances the oxidative process. TCS is stable at $50^{\circ} \mathrm{C}$ when it is kept separate from biotic contact and kept at a $\mathrm{pH}$ of 4-9. TCS degrades more rapidly in an aqueous medium at $25^{\circ} \mathrm{C}$ and $\mathrm{pH} 7$, reaching $50 \%$ in around 41 minutes. Within 4 hours after therapies, primarily 2,4-DCP is generated. TCS is easily degraded in aquatic environments by photolysis, with a half-life ranging from 1 hour in abiotic settings to roughly 10 days in freshwater sources ${ }^{62}$. Furthermore, depending on the reactivity of TCS with photochemically generated hydroxyl radicals, its aerial half-life has been predicted to be 8 hours ${ }^{63}$. Even while the current amounts of TCS and its by-products in the atmosphere are not dangerous, continued deposition of TCS into the atmosphere could approach a threshold value, affecting all categories of animals in the food chain ${ }^{64}$.

\section{OXIDATIVE STRESS MECHANISM}

If not adequately scavenged, these "two-edged sword" molecules, ROS, may disrupt the cellular redox equilibrium, resulting in oxidative harm to protein, lipids membranes, and nucleic acid ${ }^{65}$. When the dynamic balance in the synthesis and removal of ROS in typical circumstances is disturbed, "oxidative stress" is used ${ }^{66}$. The antioxidant defence mechanism, including CAT, SOD, GPx, GR, GSH, Glutathione disulphide (GSSG), and glutathione S-transferase (GST), works to counter the potentially harmful effects of ROS. As a result, ecologists may measure antioxidant levels to monitor the amount of oxidative damage induced in organisms treated with particular substances ${ }^{67}$.

\section{Catalase (CAT)}

Adult zebrafish livers treated to different dosages of TCS, SOD, CAT, and GPx enzyme activity were assessed. When the antioxidant defence fails to resist this ROS, the overwhelming generation of ROS is a potential source of enzyme inactivation. ROS elimination is caused by the change of radicals without oxygen into hydrogen peroxide molecules by SOD, further reduced into $\mathrm{H}_{2} \mathrm{O}$ by CAT and $\mathrm{GPx}^{68}$. As a result, if these critical first-line defences become less active, $\mathrm{H}_{2} \mathrm{O}_{2}$ and its degradable compounds may accumulate ${ }^{69}$. SOD activities were inhibited in all treatment groups relative to the control group, according to the research. At the lowest dose of $50 \mathrm{~g} / \mathrm{L}$, though, the caused suppression of SOD was significant $(\mathrm{p}<0.05)$ when compared to the control ${ }^{70}$. The lower concentrations of SOD activity in the treatment groups' liver tissue may be related to the ROS generated by TCS treatment. The CAT and the GPx enzymes must maintain intracellular redox equilibrium and $\mathrm{H}_{2} \mathrm{O}_{2}$ degradation ${ }^{68}$.

The activity of CAT followed a parallel path to that of SOD in the liver. There was a substantial decrease in CAT activity between the treatment and control groups $(\mathrm{p}<0.05)$. The reduction of CAT activity in the liver varies considerably between treatment groups at $\mathrm{p}<0.05$, with the effect of suppression being most noticeable at the lowest dose $(50 \mathrm{~g} / \mathrm{L})^{71}$. The apparent decrease in CAT behaviour implies that the produced $\mathrm{H}_{2} \mathrm{O}_{2}$ may not be quickly destroyed by CAT, indicating a redox imbalance in the cell. The pattern toward reduced CAT activity was lower in the liver ${ }^{72}$. Poor regulation of antioxidant enzyme activity may result in an increased amount of ROS, thus reducing the antioxidant system's efficiency. This theory is supported by the idea that increasing ROS produced the reduction in SOD, resulting in a loss in enzyme efficiency and function ${ }^{73}$.

CAT plays a vital role in the progression of ROS due to TCS toxicity (Figure 1). After subchronic treatment 


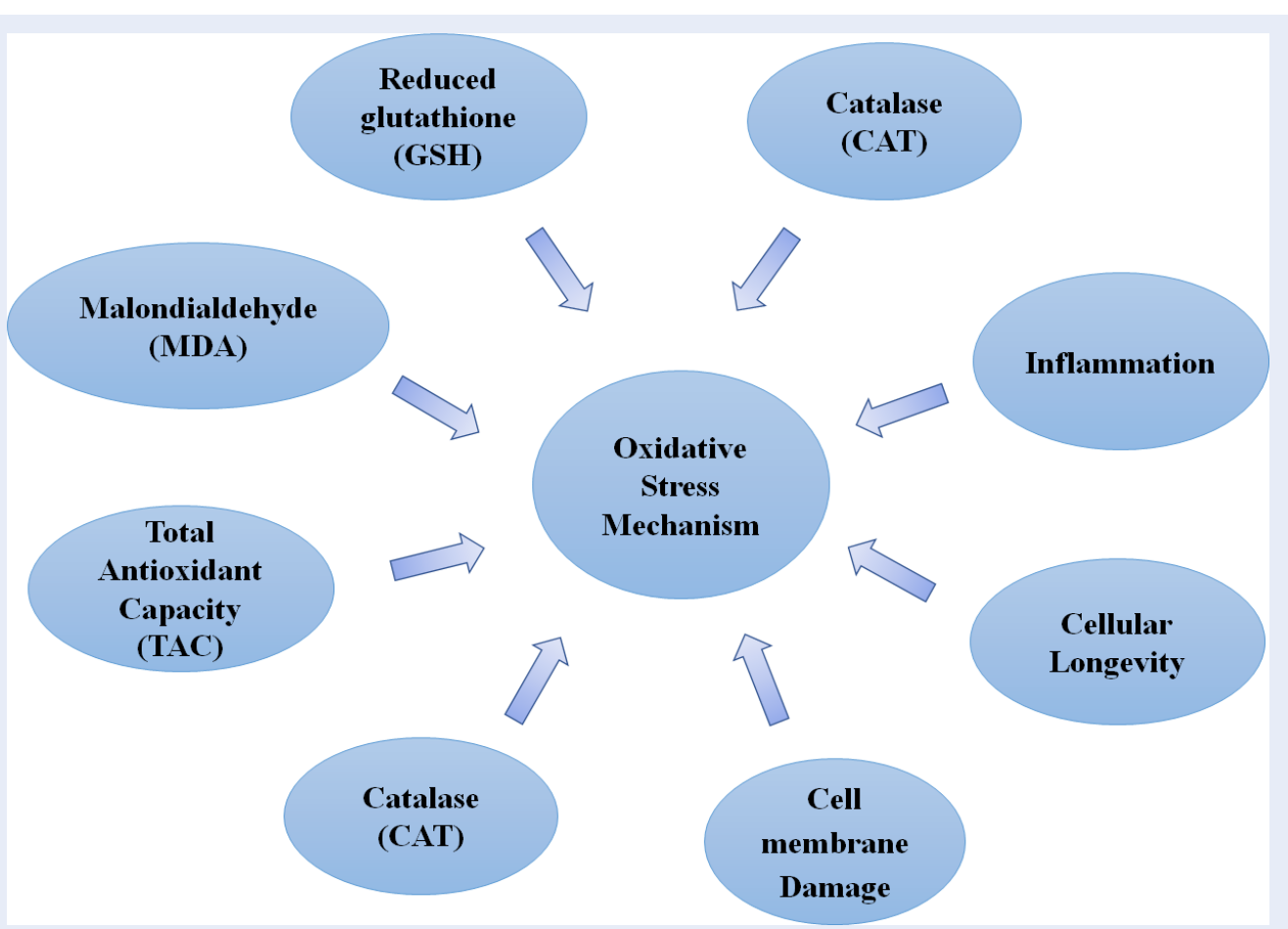

Figure 1: Various underlying mechanism of oxidative stress. Role of MDA, TAC, CAT, GSH, inflammation, cellular longevity and membrane damage have been observed that any imbalance can lead to oxidative stress.

with TCS, the enzyme activity of SOD and CAT was assessed in the brain of adult zebrafish ${ }^{74}$. CAT activity was reduced to control across treatment groups. There was a statistically significant difference in CAT activity between the control and increased TCS exposure $(100 \mathrm{~g} / \mathrm{L}$ and $150 \mathrm{~g} / \mathrm{L})$. TCS may alter the zebrafish brain's antioxidant system due to the reduction of CAT and SOD activities. Despite this, mean SOD activity in the brain was significantly greater than in the liver for both TCS treatments, whereas mean CAT function in the brain was significantly lower. The various physiological roles of the organs may describe the discrepancy in numerical ranges of antioxidant enzymatic activity ${ }^{74}$.

\section{Reduced glutathione (GSH)}

GSH and GSSG (the glutathione system) are nonenzymatical antioxidants, and also GSH enzymes are regarded as the second-line defensive mechanism for oxidative damage ${ }^{69}$. The action of GR is critical for GSH regeneration as a defence mechanism against oxidative stress. Because GSH is converted to an oxidized form, GSSG, during metabolic activity, GR recycling of GSH from GSSG is critical for sustaining the cellular antioxidant protective mechanism ${ }^{75}$. Additionally, it's important to note that GPx is involved in detoxifying ROS and $\mathrm{H}_{2} \mathrm{O}_{2}$ through the oxidation of GSH to GSSG, implying that suppression of GPx activity may impact glutathione and its conjugate levels ${ }^{9}$.

Scientists found a significant decrease in GSH concentration in adult zebrafish livers exposed to TCS compared to a control group (p0.05). GSSH concentrations were also considerably less in TCS-exposed groups than in controls $(\mathrm{p}<0.05)$. Furthermore, except for the $100 \mathrm{~g} / \mathrm{L}$ TCS exposure group, the treatment groups did not consider the decrease in GSSG concentrations ${ }^{\mathbf{7 6}}$. Following TCS exposure, the GSH/GSSG concentrations were decreased, indicating GSH levels (Figure 1). GR activity was observed to be less than control in treatment groups. Besides the $50 \mathrm{~g} / \mathrm{L}$ and $100 \mathrm{~g} / \mathrm{L}$ groups compared to the control group, the reduced GR activity was not substantial within groups $(\mathrm{p}<0.05)^{77}$. The decreased GSH/GSSG found in the current research may explain that GSH could not be revived to regain its normal concentration in the liver after treatment to TCS concentrations due to lower GPx and GR activities. The results demonstrated that adult zebrafish livers lost antioxidant mechanisms following subchronic exposure to TCS. 
In contrast to the roles of GPx and GR, the study found that treatment groups had higher GST activity in their livers than the control group. GST is a biotransformation enzyme that plays an important role in coupling glutathione with various contaminants ${ }^{68}$. GST protects cells from oxidative damage in phase II detoxification by catalysing the tripeptide GSH with electrophilic substrates. Except for the difference between the $150 \mathrm{~g} / \mathrm{L}$ groups and the control, which was notable at $\mathrm{p}<0.05$, there were no substantial variations in increased GST activity among groups ${ }^{78}$.

The research results are under the enhanced GST activity reported in zebrafish larvae challenged following TCS exposure $(250-350 \mu \mathrm{g} / \mathrm{L})^{79}$. De novo synthesis may account for the decrease in rGSH content in the cells, explaining its stable level following TCS treatment. The homocysteine molecule is linked to the production of $\mathrm{rGSH}$, and the cysteine amino acid in GSH is made from the same pool of homocysteine utilized to make S-adenosylmethionine (SAM). For methyltransferase enzymes, SAM serves as a methyl donor. As a result, the GSH system is intimately linked to DNA methylation, critical throughout embryonic development ${ }^{74}$.

\section{Malondialdehyde (MDA)}

The peroxidation of cell membrane lipids is a potential result of organisms being exposed to ROSgenerating pollutants. MDA is a result of membrane LPO and is often employed as a biomarker to indicate the degree of cell membrane damage ${ }^{80}$. The inability of the antioxidant system of the liver to remove ROS caused by TCS after subchronic exposure might explain the enhanced MDA concentrations in the liver (Figure 1). A recent study on Daphnia magna (D. magna) showed that MDA levels were significantly greater than controls after 6 hours of TCS exposure. Still, they were significantly lower after 24 and 48 hours, indicating lower MDA levels. The increase in MDA content in Eisenia fetida, according to Lin $\mathrm{D}$ et al., ${ }^{\mathbf{8 1}}$, showed oxidative stress caused by TCS. The current research found an opposite connection between MDA concentration and SOD action, rising first and then decreasing. Consequently, the decrease in MDA was likely due to the defensive activity of SOD in TCS-exposed D. magna against oxidative damage ${ }^{82}$.

In D. magna, TCS is responsible for the production of MDA, aminopyrine N-demethylase (APND), ethoxyresorufin-O-deethylase (EROD), and erythromycin N-demethylase (ERND) ${ }^{83}$. Additionally, increased amino acid levels in daphnids, like glutamate, proline, and glutamine, have been related to an overall state of oxidative stress ${ }^{84}$. TCS has been found to change the expression of stress-related proteins, including heat shock protein 70 (hsp-70) and glyceraldehyde 3-phosphate dehydrogenase (GAPDH) in D. polymorpha, in addition to $\mathrm{LPO}^{85}$. TCS exposure produced CAT, EROD, ERND, and APND in yellow catfish Pelteobagrus fulvidraco ${ }^{\mathbf{8 6}}$. Up- and downregulation of Cyp1a, Cyp3a, and Gst expression was seen in response to TCS level and duration of exposure, a trend similar to MDA production ${ }^{87}$. In goldfish Carassius auratus, TCSinduced oxidative damage was also found to have elevated MDA. After TCS exposure, the goldfish's liver showed various antioxidant enzyme responses and changes in MDA levels over a $\mathrm{pH}$ value ranging from 6 to $9^{9,82}$.

\section{Total Antioxidant Capacity (TAC)}

Antioxidant molecules, particularly those derived from plants, have grabbed scientists' attention in recent years. On the one hand, there is expanding proof of the preventive effect of vegetables and plant foods on cancer and other neurological disorders. On the other hand, there is emerging fear about the health consequences of synthetic antioxidants currently practiced as food additives ${ }^{\mathbf{8 8}}$. Antioxidant substances are free radical scavengers since they limit or postpone substrate oxidation by free radicals, leading to substantial protection of LPO in biological systems. The primary natural antioxidants found in plants, foods, and drinks are phenolic and polyphenolic compounds ${ }^{89}$. These compounds, which involve flavonols, quercetin, catechins, and anthocyanins, have common structural composition. They optimize the oxidative stability of foods and human systems through their redox characteristics which can help neutralize free radicals, quench singlet oxygen, and decompose hydroperoxides, among other things ${ }^{\mathbf{9 0}}$. The TAC was determined using the extract's reduction of Mo (VI) to Mo (V) and the synthesis of a green phosphate $/ \mathrm{Mo}(\mathrm{V})$ complex at an acid $\mathrm{pH}^{91}$. It assesses TAC that is both water-soluble and fatsoluble. The findings show that the methanol and acetone extracts have greater TAC (ascorbic acid equivalent) at low quantities. However, the variations are not statistically significant $(\mathrm{p}=0.05$ ) compared to the n-butanol extract. Furthermore, the n-butanol extract was shown to have substantial overall antioxidant activity at greater concentrations, equal to 90 $\mathrm{mg} / \mathrm{g}$ ascorbic acid ${ }^{\mathbf{1 1}}$. As the antioxidant capacity of ascorbic acid has been utilized as a benchmark against which plant extracts with potential antioxidants have 
been tested, this indicates that the n-butanol extract may have similar antioxidant components 92 .

It has been proposed that the donation of electrons is linked with antioxidant activity, which reflects the reduction in potency of bioactive substances. Antioxidants may function as reductants, and the deactivation of oxidants by reductants can be regarded as redox processes in which one of the reaction species is reduced at the cost of the other being oxidized ${ }^{\mathbf{9 0}}$. The $\mathrm{Fe}^{3+} /$ ferricyanide complex is reduced to the ferrous form when reductants, such as antioxidant compounds, are present in the samples. The extracts' reducing power increased as concentration increased, indicating that the extracts' capacity to donate electrons is sensitive at lesser concentrations. The considerably higher absorbance values of n-butanol extract than gallic acid indicates that the n-butanol extract has strong redox capability and may function as a reducing agent, hydrogen donor, and singlet oxygen quencher ${ }^{93}$. However, the extracts included the identical classes of phytochemicals, therefore the quantitative variation in antioxidant activity may be due to differences in phytochemical concentrations ${ }^{94}$. The findings indicate that the n-butanol extract has a higher concentration of antioxidants than the methanol and acetone extract ${ }^{95}$. It was discovered that the root of $A$. difformis has antioxidants that may be important in the therapeutic activity of this plant portion. These results call for more research in isolating and characterizing the bioactive molecules accountable for the antioxidant action ${ }^{\mathbf{1 2}}$.

\section{Cell membrane Damage}

Vischer and Regös may have been the first to describe TCS' antibacterial activity, which they demonstrated via topical treatment ${ }^{96}$. TCS's various action modes and cellular targets have been the subject of further research, which continues today. TCS was originally believed to react with the prokaryotic cell membrane in a nonspecific manner ${ }^{97}$. The TCS resistance of gramnegative bacteria has supported this hypothesis due to the membrane of their cells. The genetic response to TCS for M. tuberculosis has been investigated by Betts et al. (2003) ${ }^{98}$. Changes have been found in various cell wall genes transportation, detoxification, and other functions such as DNA replication and transcription. In E. coli and Rhodospirillum rubrum ( $R$. rubrum) $\mathrm{S} 1 \mathrm{H}$, many genes implicated in the membrane tension reaction pathway were investigated ${ }^{\mathbf{9 9}}$. Substantial variations in phenotypes of genetic code linked to the cell wall, flagella, cell envelope, multidrug efflux, and membrane structure were discovered during the electro-Fenton conversion of TCS.
These results add to a previous study describing increased TCS resistance from an overexpressed $a c r A B$ multidrug efflux pump ${ }^{99}$. TCS is thought to interact with the Agrobacterium tumefaciens transcriptional repressor $A c r R$, causing structural changes and blocking it from adhering to the promoter of the efflux pump $A c r A^{100}$.

In human erythrocytes, the association of TCS with the cellular membrane was also investigated. TCS caused $\mathrm{K}^{+}$outflow and visible haemolysis, implying membrane destruction while counteracting hypotonic breakdown caused by membrane enlargement ${ }^{101}$. TCS also decreased the activity of $\mathrm{Na}^{+}$, $\mathrm{Mg}^{2+}$-ATPase, and $\mathrm{K}^{+}$, which is membrane-bound. According to these findings, TCS induces membrane instability, disrupts monovalent ion movement, and alters the overall osmotic balance of red blood cells $^{102}$. Several investigations have shown proof of membrane disruption in the form of decreased integrity and permeability. Guillen J et al., ${ }^{103}$ used nuclear magnetic resonance (NMR) spectroscopic to establish how TCS interfaces with the plasma membrane. They discovered that TCS introduction into aquaphobic regions within the lipid membrane, perpendicular to phospholipid molecules.

\section{Cellular Longevity}

TCS and final cell destiny drew attention because of its application in oral hygiene items, as shown by two pivotal research on human gingival cells ${ }^{85}$. TCS leads to having a negative impact on cellular longevity (Figure 1). A new apoptotic trigger in epithelial cells may be TCS, cytotoxic to gingival epithelial cells and gingival fibroblasts. Till now, research in both human and animal model systems has taken a more concise approach to link TCS-induced cell death to other cellular rivals. Several dosages and scheduled responses were seen if TCS was applied to placental human choriocarcinoma cells ${ }^{\mathbf{1 0 4}}$. Elevated TCS levels have suppressed the release of $\beta$-human chorionic gonadotropin ( $\beta$-hCG), despite increased oestradiol and progesterone production (104). By stimulating caspase-3 and fragmenting Hoechst 3342 labelled DNA, considerable cell mortality was detected as apoptotic in furthermore to decreased growth ${ }^{104}$. Likewise, Winitthana et al. (2014) ${ }^{105}$ found that 24hour exposure to $10 \mathrm{M}$ TCS caused cell mortality and suicide in human lung cancer anoikis-resistant $\mathrm{H} 460$ cells. Nevertheless, safe levels (to $7.5 \mu \mathrm{M}$ ) improved cell development without modifying the proliferation (elevated colony counts and decreased size). TCS also encouraged cell migration and invasion, as well as the epithelial-to-mesenchymal transition (EMT). 
A research team used BG-1 ovarian cancer cells in various animals and laboratory experiments to determine how TCS influenced the development and proliferation of such cells. TCS stimulates cell proliferation and cyclin D1 gene expression and protein levels while lowering p21 and Bax genetic code appearance and protein level ${ }^{106}$. The ER antagonist ICI 182,780 greatly inhibited these impacts, implying that ER is involved in TCS-induced cell cycle development and its antiapoptotic function ${ }^{107}$. MCF-7 bosom malignancy cells and LNCaP prostate cancer cells both reacted to TCS in the same way, according to other researchers in the same group. $1 \mathrm{M}$ of TCS raised development and multiplication in MCF-7 cells over six days, with elevated cyclin D1 and lower p21 expression ${ }^{108}$. Research on the effect of TCS on cell destiny has shown that it has estrogenic, proliferative, and apoptotic properties ${ }^{109}$. TCS regulation is especially susceptible to genes and proteins that control the cell cycle and apoptosis. In addition to other research data such as cell type and exposed length, the variation in ultimately cell destiny appears to imply interracial difference and dosage reaction. Extending our understanding of the presence and identifying a precise molecular "switch" that can shift the balance in support of apoptosis or persistence could be a crucial topic of upcoming research ${ }^{14}$.

\section{Inflammation}

TCS has long been known as a successful treatment for infectious dermatitis, with the compound's therapeutic ability ascribed entirely to its antimicrobial action ${ }^{110}$. Researchers didn't establish a relationship between TCS exposure and non-infectious inflammation remission until the last two decades of the previous century. The usage of antibacterial agents as antiinflammatory therapeutic has gained much attention over the past two decades ${ }^{111}$. Anti-inflammatory activity has been demonstrated in many antibiotics, including quinolones and macrolides ${ }^{112}$.

According to Gaffar A et al., ${ }^{113}$ TCS reduced LPO synthesis, 15-LPO, 5-lipoxygenase, IL-1-induced prostaglandin E2 (PGE2), and cyclooxygenase-1 (COX-1), COX-2 in gingival cells. Additionally, TCS has been found to inhibit a broader variety of inflammatory agents, such as arachidonic acid and prostaglandin I2 (PGI2) produced by TNF-induced PGE2, IL-1 $\beta$, phospholipase A2 (PLA2), COX, and tumour necrosis factor ${ }^{114}$. Furthermore, individuals who received a mouth rinse containing 0.15 percent TCS had considerably fewer oral erythematous lesions than those who received a TCS-free mouth rinse in a crossover trial. TCS' anti-inflammatory effects had been proven and were generally acknowledged throughout the scientific and medical sectors by that time ${ }^{115}$.

To date, further research has emphasized the antiinflammatory properties of TCS. In human gingival fibroblasts, Mustafa M et al., ${ }^{15}$ found IL-1 $\beta$, IFN $\gamma$, MHC class II, and PGE synthase- 1 as TCS targets. Notably, investigations determining the subcellular location of TCS indicate priority for nucleus accumulation over cytosolic accumulation. Since the cytoplasmic TCS absorption was greater at first, following successive washing, a large percentage of cytosolic TCS was removed, whereas nuclear TCS was retained ${ }^{\mathbf{1 1 6}}$. This may account for the altered inflammatory signaling seen in TCS. MicroRNA (miRNA) regulation of the TLR pathway was responsible for inhibiting LPS-induced cytokine production and antimicrobial activity in primary human oral epithelial cells ${ }^{117}$. The results were similar in cells obtained from diabetes individuals, where the TLR response was amplified ${ }^{118}$.

On the other hand, TCS has been shown to inhibit the TLR response induced by LPS via altering miRNAs (lowering miR155s but promoting miR146a). TLR4 induced changes in inflammatory responses in mice's skin and leukocytes when they were topically challenged with TCS ${ }^{119}$. Similarly, TCS suppressed PGE2-stimulated matrix metalloproteinase13 (MMP-13) or parathyroid hormone (PTH) production in osteoblastic rat osteosarcoma cells ${ }^{\mathbf{1 2 0}}$. Since hyperactive MMP-13 has been related to periodontal disease, it's been proposed that TCS may protect against the inflammatory condition of the mouth by acting on that same enzyme, besides others ${ }^{121}$.

Notably, TCS has proven beneficial in treating various inflammatory states, such as hidradenitis suppurativa (HS) and cardiovascular disease. Furthermore, the application of TCS-drenched ureteral stents appears to become a potential strategy for treating urinary tract infection (UTI) and inflammation. In pregnant women, an enhanced urinary TCS was linked to an elevation in serum IL-6, suggesting a potential pro- or anti-inflammatory function ${ }^{122}$. TCS is a mediator of immunological and inflammatory responses, as shown by the abundance of data available. Nonetheless, mounting evidence suggests that TCS significantly amplifies and worsens the ultimate result when a pre-existing unfavourable state, like inflammation or tumour, is present ${ }^{14}$. 


\section{Cellular Signalling}

The ability to adapt to the continuously shifting intracellular and external environments is greatly facilitated by communicating efficiently. The transmission of data containing particular commands is carried out by carriers that work sequentially along a specified way. Moreover, tasks are often performed by sequentially transducing numerous signals via a complicated, intertwining network, including a diverse array of mediators $^{123}$. As a result, the relevance of cell signaling cascades in response to xenobiotics must not be overstated.

Cell lines of humans have given a lot of knowledge, especially in researching stressors and xenobioticsensitive signalling molecules like TCS (Figure 1). The conventional MAPK has also been implicated as TCS targets ${ }^{124}$. The TCS-induced proliferation of JB6 $\mathrm{Cl} 41-5 \mathrm{a}$ cells was aided by the activation of c-Jun $\mathrm{N}$-terminal kinases (JNK), p38 MAPKs, and ERK1/2, in addition to $\mathrm{Akt}^{125}$. Proliferation induced by TCS was significantly reduced when phosphoinositide 3kinase (PI3K) or MEK1/2 were inhibited. According to the results of another study on rat neural stem cells, cytotoxicity and apoptosis induced by TCS were linked to stimulation of the JNK and p38 pathways, as well as blocking of the ERK, Akt, and PI3K pathways ${ }^{126}$. This indicates that these proteins are involved in both cellular stability and mortality due to TCS's action. Studies used the hypothalamus from Sprague-Dawley rats and Human Nthy-ori 3-1 thyroid follicular cells to demonstrate that TCS stimulates p38 and $\mathrm{JNK}^{\mathbf{1 2 7}}$. In that research, TCS affected the amount of thyroid peroxidase (TPO) via stimulating the thyrotropin-releasing hormone receptor via $\mathrm{p} 38 \mathrm{MAPK}^{\mathbf{1 2 8}}$. TCS reduced AP-1 sequence and Fos/Jun interaction within the C-fos promoters and Mmp-13, which reduced Mmp-13 synthesis in mouse osteoblastic osteosarcoma cells ${ }^{120}$.

The researchers were particularly interested in TCS's endocrine-disrupting properties, particularly its estrogenicity. Kim YS et al., ${ }^{106}$ demonstrated that TCS induced BG-1 ovarian cancer cells proliferation via the ER $\alpha$. Proving the function of ER, the application of ICI 182,780 restored TCS proliferation characteristics along with related modifications at the levels of cyclin D1, p21, Bax, and protein. Similarly, following TCS treatment, the ER was involved in MCF-7 cell proliferation and an increase in the size of breast tumours in mice ${ }^{109}$. The suppression of TCS by ICI 182,780 or kaempferol, as well as the activation of insulin-like growth factor (IGF), particularly pIRS-1, $\mathrm{PKB}, \mathrm{MAPK}$, and $\mathrm{pERK} 1 / 2$, supported this theory ${ }^{30}$.
In addition, kaempferol reduced the development of VM7Luc4E2 cells stimulated by TCS ${ }^{29}$. These findings are consistent with those of Huang et al., ${ }^{129}$, who previously described the estrogenic activity of nanomolar doses of TCS in identical cells.

The TCS has a dual impact on ER signaling, according to new research. For instance, Henry and Fair ${ }^{33}$ showed that TCS at concentrations ranging from $7 \mathrm{nM}$ to $700 \mathrm{M}$ shows estrogenic action when given solely to MCF7 cells but becomes antiestrogenic when combined with E2. According to research, TCS has little effect on rat uterine development, but it may help ethinylestradiol (EE) perform better ${ }^{130}$. TCS enhances EE-induced suppression of ER and ER expression in independent research but does not stimulate ER when given alone at dosages ranging from 30nM to $100 \mathrm{M}$. According to the study, TCS also reduced E2 and oestrogen sulfotransferase efficiency in the sheep placenta $^{131}$. In contrast, a TCS-derivative combination produced enhanced $\operatorname{ER} \beta$ activity but not $\operatorname{ER} \alpha$, resulting in neurological and psychological problems in zebrafish ${ }^{132}$. ICI 182,780 and RU 486 restored both abnormalities, suggesting that the antimicrobials may have an estrogenic effect.

In terms of TCS's androgenic characteristics, it was discovered that TCS inhibits-TSN-associated transcription while promoting androgen-dependent transcription ${ }^{133}$. According to Riad MA et al., ${ }^{134}$, TCS therapy alone or in combination with butylparaben reduced TSN, follicle-stimulating hormone (FSH), and luteinizing hormone ( $\mathrm{LH}$ ) levels in weanling male rats. At the same time, it increased E2 after a single TCS treatment. Bicalutamide, an androgen receptor (AR) antagonist, significantly inhibited TCS-induced proliferation and translocation of LNCaP cells.

Protein structure and dynamics are affected by calcium levels inside cells. Conversely, $\mathrm{Ca}^{2+}$ binding to proteins help maintain the ion's concentration in a physiological limit while simultaneously activating various cellular functions such as gene expression, movement, secretion, and longevity ${ }^{135}$. Apart from proteins, several factors, like xenobiotic exposure, affect intracellular $\mathrm{Ca}^{2+}$ concentration. TCS increased cytosolic $\mathrm{Ca}^{2+}$ in primary skeletal myotubes in a dose-dependent manner, regardless of exogenous $\mathrm{Ca}^{2+}$, via the $\mathrm{Ca}^{2+}$ channel ryanodine (Ry) receptor type 1 (RyR1) ${ }^{26}$. Accordingly, in vitro and in vivo exposure to TCS was impaired by muscle contractility ${ }^{136}$. TCS also disrupted the two-way communication in RyR1 channels and $\mathrm{Ca}^{2+}$ ions by inhibiting $\mathrm{Ca}^{2+}$ entry mediated by excitation ${ }^{137}$.

The data on the xenobiotic reaction to TCS has shown that TCS activates or suppresses many signaling pathways. Depending on the experimental 
circumstances and model under study, diverse results occur across species and even within the same species ${ }^{138}$. Although significant advancements in TCS signaling have been accomplished yet, there is still much to learn about TCS's modulatory impacts on cellular physiology, particularly in human-based systems. TCS therapy has an unknown impact on many human cell types and tissues, so it's critical to determine which signaling pathways are involved in cellular development, metabolism, and general activity ${ }^{14}$.

\section{ESTROGENICITY}

TCS, an antibacterial molecule, has a negative impact on human genotoxicity, and its antiandrogenic capability damages DNA. TCS has induced IP at a dosage of $15 \mathrm{mg} / \mathrm{kg}$ for two days in a row. TCS therapy results in a substantial reduction in testicular hormones (testosterone FSH and LH) ${ }^{139}$. TCS's impact on the environment and human health. TCS is prooxidant and cytotoxic in a variety of ways, according to cell research. TCS is involved in both estrogenicity and anti-estrogenicity in cancer development ${ }^{140}$. TCS research on surface water and wild fish. TCS and a binary combination with BE2 had a negative impact on testicular growth and reproduction in fish at a dosage level of TCS $117.9 \mathrm{mg} / \mathrm{L}^{\mathbf{1 4 1}}$.

\section{MUTAGENICITY}

The mutagenic capability of TCS has been studied in several ways, including in vitro and in vivo tests that look for point mutations, recombination events, and frame shift mutations in prokaryotic and eukaryotic systems. On TCS, in vitro microbial reverse mutation tests (Ames Assays) were performed ${ }^{\mathbf{1 4}}$. Various Salmonella typhimurium (S. typhimurium) strains, with or without $S 9$ metabolic stimulation, were employed in vitro tests using TCS. Muller D et al., ${ }^{142}$ also investigated the mutagenicity of TCS in a bacterial reverse mutation test using intrasanguineous hosts. All findings from these reverse mutation tests in vitro and host were negative. It showed that TCS did not induce gene mutations ${ }^{143}$.

Gene mutation investigations in mammalian cells via in vitro model suggested that metabolic stimulation of mouse lymphoma L5178Y cells with and without TCS has shown the ability to produce mutations in the TK region of a gene ${ }^{\mathbf{1 4 4}}$. In host-mediated research in mice, Müller D et al., ${ }^{\mathbf{1 4 5}}$ investigated the mutagenicity of TCS at the TK gene in mouse lymphoma L5178Y cells, finding no treatment-related changes in malformation rate. There was no rise in the mutant rate at doses that did not cause cell death (up to $20 \mathrm{~g} / \mathrm{ml}$ without $\mathrm{S} 9$ and up to $15 \mathrm{~g} / \mathrm{ml}$ with $\mathrm{S9}$ ).

However, De Salva et al., ${ }^{146}$ and Bhargava et al., ${ }^{147}$, continue to believe that TCS is not a mutagen, and antimicrobial individual care items are not harmful to one's health. Despite the positive results of the mammalian spot test, most of these tests revealed that TCS had no mutagenic ability. Fahrig R et al., ${ }^{148}$ was the first to conduct the mammalian spot test and yielded a positive result, but was later replicated by Russell et al. (1980) ${ }^{149}$ yielded negative results. Fahrig R et al., ${ }^{148}$ have been challenged, claiming that the optimal TCS dosage could produce maternal toxicity, preventing offspring evaluation. It's unclear why these two types of research, which used the identical methodology, produced such disparate findings. Fahrig R et al., ${ }^{148}$ employed a larger dosage of TCS soluble in hank's balanced salt solution (HBSS). In contrast, Russell LB, and Montgomery C. et al., ${ }^{149}$ found TCS insoluble in HBSS and consequently applied methanol to dissolve the antibiotic. Russell LB and Montgomery C. ${ }^{149}$ assumed that the Fahrig R et al., ${ }^{148}$ investigation was unsuccessful in inserting one of the TCS dams because the absorption of the TCS in HBSS was restricted, explaining the toxicity at $50 \mathrm{mg} \mathrm{kg}^{-1}$. It was extremely hazardous to embryos ${ }^{149}$. Many scientists appear to endorse this study observations ${ }^{149}$ as TCS safety reviews.

The researchers have carried out three-wide genomic DNA (0.2T-AMX, 0.2T-CHL, and 0.2T-TET) sequencing for reproduced mutants induced by TCS ( $\mathrm{n}$ $=6)$ and for wild strain E. coli $(n=2)$ to find important genetic modifications of antibiotic resistance caused by TCS. When compared to non-treated E. coli, sequencing of 6 resistant mutants produced following treatment of TCS at $0.2 \mathrm{mg} / \mathrm{L}$ showed 14 genetic modifications in 11 genes and 9 alterations in intergenic regions. The $+\mathrm{A}$ insertion in the insB-1 gene was seen in all sequenced mutants, along with substitution alterations in the fabI genetic code ${ }^{150}$. Because TCS interacts with the enoyl reductase FabI, which is expressed by the fabI chromosome, genetic variations in the fabI chromosome may impair TCS effectiveness by altering the shape of the targeted fabI protein ${ }^{151}$. Apart from the typical mutations, several strain-specific mutations have been discovered. The citC (A346T), acrR (L65R), and soxR (R20S) substitute alterations, for example, were detected solely in the $0.2 \mathrm{~T}$ CHL strains. In comparison to other strains, the 0.2 T-TET strain contains a $1 \mathrm{bp}$ frameshift in the insl-1 genetic coding and a replacement variation in the marR chromosome (T72P) ${ }^{152}$. At the same time, transcriptional analysis was used to identify the 
molecular processes behind TCS-induced antibiotic resistance. Complete genome Illumina RNA sequencing was used to see how three mutant kinds $(n=9)$ and wild-variant E. coli $(\mathrm{n}=3)$ responded to the 8-hour $0.2 \mathrm{mg} / \mathrm{L}$ TCS treatment. Acute TCS treatment leads to typical transcript alterations between mutants and wild-kind $E$. coli compared with untreated wild-kind E. coli $(\mathrm{n}=3)^{151}$. In contrast, the cellular antioxidant genes soxS, yhcN, and YgiW and the membrane encoding porin gene ompX have decreased ${ }^{153}$. TCS induces oxidative stress in $E$. coli at a concentration of $0.2 \mathrm{mg} / \mathrm{L}$, while simultaneously reducing the regulation of genes that encode antioxidants, activating the SIM response to DNA deterioration ${ }^{152}$.

TCS-induced genetic changes may have enhanced antibiotic tolerance by modulating the genetic code's appearance concerning antibiotic resistance. Since the promoter of the gene $a m p C$ encoding beta-lactamase overlaps the $f r d D$ gene space in E. coli $\mathrm{K}-12^{154}$. The frdD alteration observed in 0.2T-AMX mutants could have impacted the $\operatorname{ampC}$ supporter endurance ${ }^{\mathbf{1 5 5}}$, resulting in greater ampC expression ( $\log 2$ fold change $(\mathrm{LFC})=5.4)$ and elevated beta-lactam antibiotic tolerance $^{\mathbf{1 5 6}}$. Furthermore, soxR gene alteration may cause a spike in soxS expression ${ }^{157}$, leading to a rise in efflux via boosting $a c r A B$ regulation ${ }^{158}$. As a result of the overexpression of the $A c r A B$ many drugs exporter channel, multiple antibiotic resistance is likely to occur ${ }^{159}$. Mutations in the marR gene may have reduced adhesion capacity in $0.2 \mathrm{~T}$-TET mutants, resulting in upregulation of $\operatorname{mar} A B$ genes that control overall multidrug resistance ${ }^{\mathbf{1 6 0}}$. As a result, $\operatorname{Mar} A B$ may have sparked the development of an antibiotic resistance genes cascade, including GadAB-YadGH and $A c r A B-T o l C^{\mathbf{1 6 1}}$.

\section{CARCINOGENICITY}

TCS is a diverse antibiotic negotiator often used in cosmetics, toothpaste, and other consumer goods. Queries have been expressed about the blend's wideranging use in customer goods and its recognition in bosom milk, pee, and sera. It's possible linked to a variety of human health effects ${ }^{\mathbf{1 6}}$. The compound's extensive use in consumer goods, as well as its presence in bosom milk, pee, and sera, has sparked worries about its possible link to a variety of human health effects. Recent data put forward that TCS can serve a part in cancer growth, possibly due to its estrogenic properties or propensity to suppress fatty acid production $^{16}$.

The most common mechanism of endocrine disturbance by exogenous substances is the suppression of the internal secretion (hormones) from attaching its receptor sites by trying to compete for sense-organ linkage locations with the competitor ${ }^{\mathbf{1 4 0}}$. This is one of the mechanisms via which TCS causes endocrine dysfunction $^{26}$. It is well established that when a ligand binds to a receptor site, it induces conformational changes in the sense-organ, resulting in the synthesis of transcription factors essential for the representation of internal secretion sensitive genes ${ }^{\mathbf{1 6 2}}$. Hypospadias, cryptorchidism, and cancer are uncontrollable physiological outcomes of the antagonist's representation of oestrogen-sensitive genes ${ }^{\mathbf{1 4 0}}$.

Carcinogenicity and precocious puberty might be interpreted as a result of receptor overstimulation, presumably caused by the high TCS level, or as a result of TCS occupying the receptor's ligand engaging domain ${ }^{33}$. More research is needed to link TCS concentrations in the environment with observed physiological consequences in animals, such as unfavourable fertility impacts. However, the in vivo toxicity of TCS has not been established accurately, noticeable concentrations of the substance in exposed humans' body fluids. TCS bio-accumulates and is widely dispersed in human tissues, as evidenced by the increased TCS levels in tissues compared to ambient levels ${ }^{26}$.

There have been reports of human beings developing allergic responses to TCS. Extensive usage of TCScontaining hand detergents has been linked to dermatitis or subsequent exposure to sunshine ${ }^{163}$. Similarly, after extended usage of toothpaste containing TCS, lesions have been reported to occur in the oral cavity and on the lips of human patients ${ }^{164}$. Elevated TCS concentrations in urine have been linked to immunological malfunction, allergic responses, and the development of asthma in children ${ }^{165}$. TCS has been shown to modify the structure of human serum albumin ${ }^{166}$. Endogenous molecules are obstructed by toxic substances attached to serum albumin and alter the shape of the protein molecule, thereby impairing its function or even altering its physiological activity. Researchers found that greater urinary concentrations of TCS were associated with lower fecundity in women ${ }^{88}$.

Xenoestrogens are oestrogen-like chemicals widely present in cosmetics, insecticides, and plastic bottles. Xenoestrogens interact with oestrogen attachment to oestrogen receptors in the human body, resulting in oestrogen-dependent health consequences such as maturation, reproductive health, and fertility ${ }^{167}$. TCS is a less well-known xenoestrogen with antimicrobial properties often found in cosmetic products, toothpaste, detergent, and other consumer goods. The ubiquitous usage of TCS, along with its presence in pee, sera, and in women's bosom milk, 
has prompted concerns about its link to various health consequences, including cancer ${ }^{168}$. According to an existing study, TCS can be estrogenic and antiestrogenic $^{33}$. Recent evaluations imply that TCS is estrogenic at lower concentrations because it promotes female sex hormone-sensitive bosom cancer cells. TCS inhibits the development of these cells at increasing concentrations, implying that higher doses may have an anti-estrogenic impact ${ }^{169}$.

The impacts of TCS on bosom cancer cells in vitro may be affected by concentration and other variables like oestradiol (natural oestrogen) ${ }^{\mathbf{1 7 0}}$. Untimely bosom development, antimicrobial opposition, and hypersensitivity are possible health consequences ${ }^{171}$. However, the existence of TCS in milk indicates that it has passed through the human bosom, raising worries about its potential role in developing bosom cancer $^{170}$. Plasma and sewage from people indicate the systemic transfer of TCS to humans, although local absorption from cosmetic goods applied to the bosom region is another exposure mechanism. TCS is a type 1 FAS enoyl-reductase blocker that is impactful against the bosom cancer cell lines MCF-7 and SK Br-3 in cultured cells ${ }^{172}$. The disruption of human FAS through a different method and at various active sites reinforces the idea that type 1 FAS could be a chemotherapeutic goal. It also implies that inhibiting any of this multipurpose enzyme's activity could be useful ${ }^{31}$. When a substance is so widely diffused in the aquatic environment, it can induce an endocrine disruption in aquatic animals, which is a reason for concern. The early investigations in medaka fry (Oryziaslatipes) indicated that TCS could be slightly androgenic based on alterations in fin size and sex ratio fluctuations ${ }^{173}$. TCS has been demonstrated to bind to proteins in other investigations. In North American bullfrogs, it binds to thyroid hormone receptors and disrupts their endocrine system ${ }^{174}$. TCS can potentially cause endocrine disruption by raising thyroid hormone levels. Thyroid hormone levels above a certain threshold may indicate a greater chance of getting bosom cancer ${ }^{175}$. Thyroid dysfunction is more common in bosom cancer patients than in healthy people, although no clear link has been discovered ${ }^{\mathbf{1 7 6}}$.

Environmental chemicals may harm human health and induce carcinogenesis, according to accumulating data. TCS enhances the release of the VEGF, a substance that promotes tumour development ${ }^{177}$. This process involves the direct stimulation of a membrane ion channel which causes an elevation in intracellular calcium levels. In primary cultivated human prostate cancer, stromal cells show that ecologically significant levels of TCS activate a TRP family, TRPA1 (Transient Receptor Potential Ankyrin 1), using calcium imaging and electrophysiological approaches. TRPA1 activation of TCS raised baseline calcium in stromal cells, boosted VEGF production, and enhanced epithelial cell proliferation ${ }^{178}$. Immunofluorescence labelling of prostate tissue in formalin fixation and paraffin embedding revealed that the TRPA1 channel was expressed only in prostatic adenocarcinoma stromal cells ${ }^{\mathbf{1 7 9}}$. Although the tumour's androgen reliance has long been known, epidemiological studies imply that elements from a Western lifestyle can also take part in its growth ${ }^{\mathbf{1 8 0}}$. Prostate cancer growth and development are thought to be influenced by epithelial-stromal interconnections ${ }^{181}$. Carcinomas are two interconnected parts: neoplasia epithelia cells and the supportive tumour stroma, which secretes cytokines and growth factors to control key procedures such as tumour propagation, vasculature, and penetration ${ }^{182}$

\section{GENOTOXICITY}

TCS and triclocarban effect on the Tetrahymena thermophila (T. thermopohila) inhibit T. thermpohila with $24 \mathrm{~h} \mathrm{EC} \mathrm{E}_{50}$ values of 1063 and $295 \mu \mathrm{g} / \mathrm{L}^{-1}$. Respectively both TCS and TCC significantly damage DNA $^{183}$. The study of TCS on goldfish for 28 days results in TCS damage the erythrocyte tail DNA ${ }^{184}$. The dose of $0.125 \mathrm{mg} / \mathrm{L}^{-1} \mathrm{did}$ not affect the size and shape of the cell. But the dose of $0.5 \mathrm{mg} \mathrm{L}^{-1}$ affects sexual reproduction and damages dependent DNA standards ${ }^{184}$. The broad spectrum TCS study on the zebrafish had a ratio of $0,17,34,68 \mu \mathrm{g} / \mathrm{L}$ TCS for 42 days. Antioxidant-related gene at 34 the gills were significantly down-regulated as compared to $68 \mu \mathrm{g} / \mathrm{L}$. In the 34 and $68 \mu \mathrm{g} / \mathrm{L}$ TSC groups, the Bax gene was substantially up-regulated in the ovary. In zebrafish, a greater dosage of TSC may induce oxidative damage in the gills and ovaries, as well as a faster ROSdependent ovary opposite ${ }^{\mathbf{1 8 5}}$.

The pharmaceutical, personal care products found in the aquatic ecosystem for a decade have a potent biological effect in the non-target organism. TCS genotoxicity increased dose-dependent at different dose levels TCS $0.1,0.15,0.2,0.3 \mathrm{M}$ used to prevent the effect of antibacterial TCS and antibiotic trimethoprim (TMP). Significant DNA damage at extremely low levels affects haemocyte functioning ${ }^{\mathbf{1 8 6}}$. The trail TCS was conducted on goldfish (Carassius qurtus) the dose level (control, DMSO control, and $\frac{1}{2}, \frac{1}{4}$ and $1 / 8$ $\mathrm{LC}_{50}$ ) effect of genotoxicity and micronucleus $(\mathrm{MN})$ and nuclear abnormalities (NA) frequencies in peripheral blood. TCS $96 \mathrm{~h}$ median lethal concentration 
was $1111.9 \mu \mathrm{g} / \mathrm{L}$ significantly increase $\mathrm{MN}$ and $\mathrm{NA}$ frequencies TCS cause oxidative stress and a genotoxicity response in goldfish ${ }^{9}$.

Different doses of TCS response increased in the proliferation of MCF7 DOS cells elicited by E1. The TCS is at $76-87 \%$ and $68-95 \%$ at the maximum level. MCF7 Bos cell significantly increased by PFOS and 0.01 and $30 \mathrm{~kg} \cdot \mathrm{ml}^{-1}$ proliferative response of $116 \%$ of the maximum E2 ${ }^{33}$. According to research, TCS at $0.5 \mathrm{mg} / \mathrm{L}$ reduced the development of the unicellular alga Closterium ehrenbergii and caused DNA damage $^{187}$. The MN test TCS caused substantial DNA genetic damage in single-cell gel electrophoresis at all doses $(1,2,3 \mathrm{M})^{187}$. TCS increases hepatocyte proliferation-induced fibrogenesis, produces oxidative stress, and boosts inflammatory response, according to in vivo and in vitro studies using different biomarkers $^{188}$.

\section{Micronucleus (MN)}

The $\mathrm{MN}$ and NA are the most significant cytogenetic damage assays for genotoxicity ${ }^{189}$. A most sensitive method for DNA strand breakdown individual cell genotoxicity test in fish. MN frequencies in zebrafish subjected to the maximal TCS dosage.

\section{Nuclear Abnormalities (NA)}

The smear was fixed in absolute methanol for $10 \mathrm{~min}$ utes, air-dried, and stained with $10 \%$ Giemsa stain for 8 minutes in a study of MN and NA. MN and NA rates were significantly different in the TSCtreated group ${ }^{190}$. The haemocytes' genetic damage was substantial at all three TCS doses, and it followed a concentration- and time-dependent pattern. The comet test in Artemia salina was also used to assess TCS's genotoxicity ${ }^{191}$.

\section{NOVEL TREATMENT STRATEGIES}

Normal cells can convert into cancer cells due to a variety of genetic and environmental factors. It causes them to develop abnormally and propagate to many other body areas by disrupting regular cellular mechanisms such as DNA synthesis, cell division, and suicide, resulting in fatal disorders ${ }^{193}$. The basic cancer treatments are surgery, radiotherapy, chemotherapy, and adjuvant medicines such as biological gene or hormone therapies ${ }^{194}$. TCS's initial particular action strategy in prokaryotic cells was only discovered twenty years ago when it was shown that TCS inhibited fatty acid production in E. coli ${ }^{195}$. By replicating its native substrate in vivo, TCS blocked the fatty acid manufacturing enzyme enoyl-ACP reductase permanently (Figure 2). TCS resistance in the bacteria was also conferred by a mutant or overexposed ACP expressed by fabI. ACP be identified as an intracellular TCS goal as a result of these studies. Cerulenin, mycotoxin effectiveness that inhibits fat formation in inhibiting tumour development in vivo has inspired multiple papers in favour of fat formulation suppression as a new approach for chemotherapy ${ }^{196}$. FAS appearance and action vary in normal and cancerous tissues, with the latter being increased, implying a potentially high therapeutic index. TCS is a good option for chemotherapy because of its long history of human use and widespread presence in consumer goods, as well as promising in vivo outcomes ${ }^{197}$.

Phytoestrogens generated from vegetables and fruits have long been considered alternative remedies for human disorders as natural chemicals. Phytoestrogens as hormone replacement therapy (HRT) are used in protracted therapies to prevent oestrogenresponsive malignancies, such as bosom cancer ${ }^{198}$. Polyphenolic substances, such as flavonoids, have been shown in vitro and in vivo to limit bosom cancer cell proliferation by challenging with $17 \beta$-oestradiol (E2) for ER attraction sites ${ }^{199}$ as shown in Figure 2. Further comprehensive underlying mechanisms have to be researched as interest in phytoestrogens' positive effects rises ${ }^{\mathbf{2 0 0}}$. Flavonoid-based phytoestrogen kaempferol occurs mainly in fruit and plants like apples, tomatoes, and green tea ${ }^{29}$. The anti-cancer and osteosarcoma effect of kaempferol has been described in current studies ${ }^{\mathbf{1 9 2}}$. It has been reported in many studies that extensive usage of TCS can have cancerogenic potential, as shown in Table 1. Significant research has also highlighted the mechanisms involved in kaempferol anticancer action associated with the cell cycle, cell death and angiogenic, inflammatory reactions, and oxygen radicals production ${ }^{201}$. In U-2 OS human osteogenic sarcoma cells, kaempferol also reduced the appearance of ERK, JNK, and p38 ${ }^{202}$. Kaempferol inhibited the PI3K/Akt signal transduction by adhering directly to PI3K and inhibiting the capabilities of AP-1, and protein kinase b (NF- $\beta$ ), which affect a variety of cellular activities such as growth, angiogenesis, and death ${ }^{203}$. According to an in vitro study, TCS can enhance the growth of BG-1 ovarian cancer cells by modulating the expression of cell cycle and death genes ${ }^{19}$.

To investigate for signalling-related genes in MCF7 cells treated with Dimethyl sulfoxide (vehicle), E2 (109 M), TCS (106 M), and a blend of kaempferol $(50 \mathrm{M})$ and TCS, we conducted western blotting on specimens of proteins recovered from the cells ${ }^{204}$. Given the discoveries, E2 was up-regulated. IRS-1, $\mathrm{PKB}, \mathrm{MAPK}$, and phosphorylated versions of IRS-1 


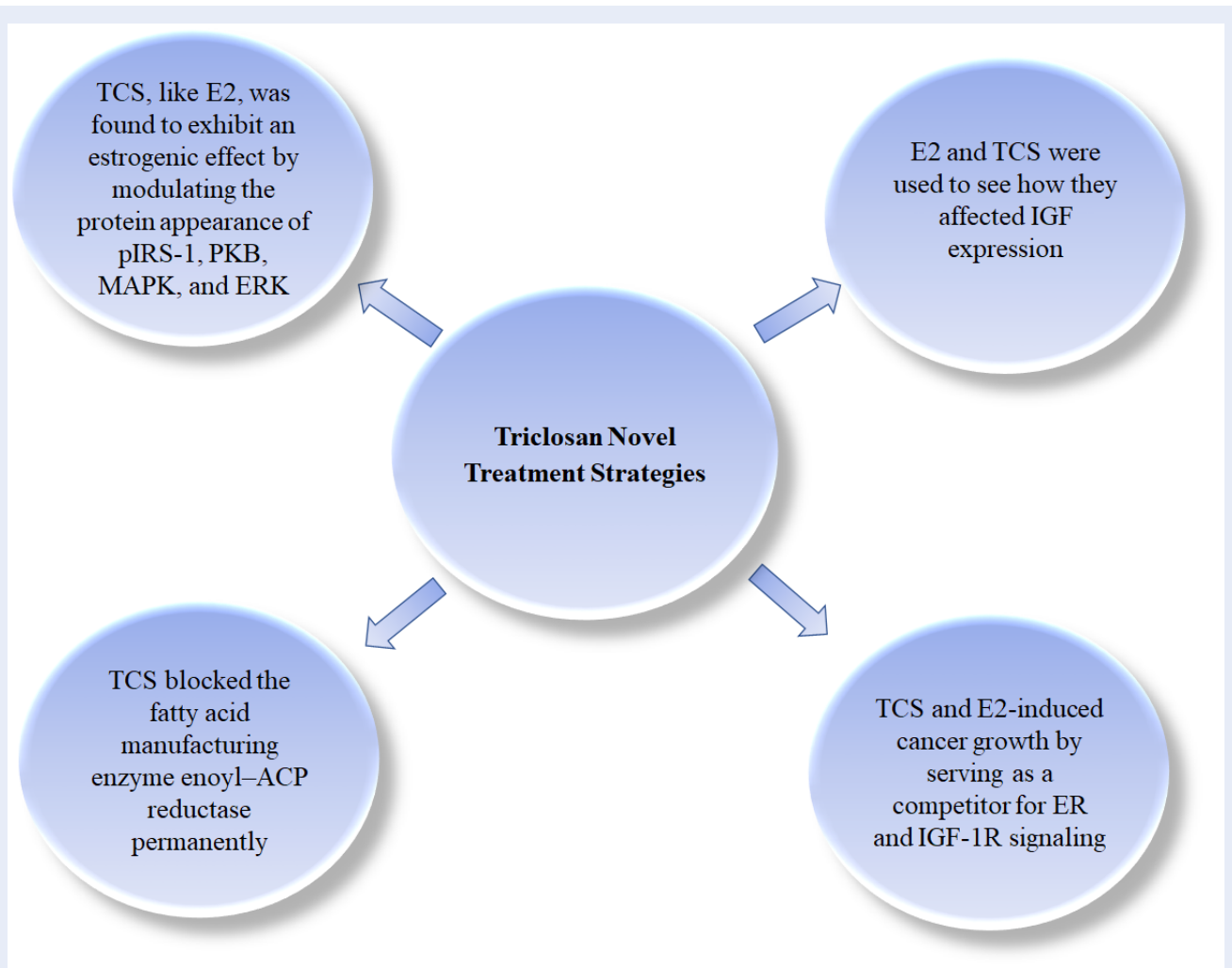

Figure 2: Treatment strategies of TCS. TCS inhibits the protein synthesis of pIRS-1, PKB, MAPK, and ERK. E2 activates major proteins of ER and IGF-1R signaling pathway. TCS also inhibits enzyme enoyl-ACP reductase. So, all treatment strategies influence the signaling pathways to keep the balance and reduce the damage.

Table 1: Studies demonstrating TCS-mediated cancer types with the underlying mechanism

\begin{tabular}{|c|c|c|}
\hline Concentration of TCS & Effects & References \\
\hline $0.0028-28.9 \mu \mathrm{g} / \mathrm{ml}$ & Estradiol antagonism & 26 \\
\hline $0.00002-28.9 \mu \mathrm{g} / \mathrm{mL}$ & Cell proliferation, estradiol antagonism & 170 \\
\hline $0.002-200 \mu \mathrm{g} / \mathrm{mL}$ & Cell proliferation, estradiol antagonism, cytotoxicity & 33 \\
\hline $0-20 \mu \mathrm{g} / \mathrm{mL}$ & FAS inhibition, reduced cell viability & 3566 \\
\hline $0-100 \mu \mathrm{g} / \mathrm{mL}$ & $\begin{array}{l}\text { FAS inhibition reduced cell viability non-toxic to normal } \\
\text { cells }\end{array}$ & 32,36 \\
\hline $1 \mu \mathrm{M}$ & $\begin{array}{l}\text { Activate transient receptor potential Ankirin-1 (TRPA- } \\
\text { 1) in human prostate cancer stromal cells }\end{array}$ & 178 \\
\hline $0.1-10 \mu \mathrm{M}$ & Proliferation and anti-apoptosis inhibit ROS production & 109 \\
\hline $10-6 \mathrm{M}$ & $\begin{array}{l}\text { Up regulate pIRS-1, PKB, and MAPK in breast tumor } \\
\text { growth }\end{array}$ & 192 \\
\hline 10,100 and $200 \mathrm{mg} / \mathrm{kg}$ & $\begin{array}{l}\text { Induce mouse liver tumor via CAR and PPAR } \alpha \text { activa- } \\
\text { tion }\end{array}$ & 147 \\
\hline $10-5-10-7 \mathrm{M}$ & $\begin{array}{l}\text { Induce proliferation of breast cancer cells through ER } \\
\text { pathway and activated CXCR } 4 \text { receptor involved in } \\
\text { metastatic behavior }\end{array}$ & 29 \\
\hline
\end{tabular}


are all expressed in phosphorylated forms (Figure 2). The major proteins of insulin-like growth factor type 1 receptor (IGF-1R) signalling are the ERK proteins. E2 stimulates MCF-7 cell growth through both the ER and IGF-1R signalling pathways. E2 and TCS were used to see how they affected IGF expression (Figure 2). TCS, like E2, was found to exhibit an estrogenic effect by modulating the protein appearance of pIRS-1, PKB, MAPK, and ERK. Kaempferol also had an antiestrogenic impact by inhibiting the protein production of pIRS-1, PKB, MAPK, and ERK, which were all induced by $\mathrm{E} 2$ or $\mathrm{TCS}^{30}$. As previously stated, changes in the result of TCS therapy are primarily dependent on the experimental setup. Furthermore, limited evidence from animal research suggests that TCS treatment exacerbates the disease in the existence of a previously established tumour ${ }^{29}$.

\section{FUTURE PERSPECTIVE}

TCS is not effectively controlled, as seen in numerous environmental media, human bodies, and wildlife. Its reckless usage and disposal may endanger humans and the ecology as a whole. TCS has been demonstrated to be harmful to a variety of cells in cell-based investigations. Cell-based assays are time-limited and so cannot rightly examine the consequence of persistent expose. TCS recognition in human fluid or tissue may not have been a reliable predictor of the extended period because the evidence on its bioaccumulation in the flesh is lacking ${ }^{205}$.

Furthermore, TCS is considered to block enzymes involved in its decomposition ${ }^{\mathbf{2 0 6}}$. There is currently a scarcity of information about TCS's pharmacokinetics and pharmacodynamics. Enough knowledge would allow for more flexibility in determining TCS's toxicity. However, its anti-growth influence has been noted in certain malignant cells, the toxicological importance of TCS' inhibitory impact on human FAS is not fully grasped ${ }^{104}$. TCS has been found in significant amounts in mammalian tissues, raising the likelihood that the molecule has an adverse effect on mammalian anatomy. Its negative impact on birth resistance has been documented, as clinical reports claim it can treat human allergic skin conditions ${ }^{207}$.

TCS's exact function in selecting antibiotic resistance genes and many drugs protection genetic codes in the surroundings remains resolute. The level of the TCS needed for ecological tolerance choices also needs to be determined. The correlation between TCS introduction and bioaccumulation in an earthly organism is still unclear ${ }^{208}$. More research is needed, such as the movement of soil-based TCS processing and earth organisms absorption, including Invertebrates and slug, essential to crop production and $\operatorname{diet}^{208}$. TCS increased MCF-7 bosom cancer reproduction via modulating cell division, death, and tumour-linked genetic codes through nongenomic ER signalling linked to IGF-1R signalling.

On the other hand, Kaempferol showed an antiproliferative effect against bosom cancer by inhibiting TCS and E2-induced cancer growth by serving as a competitor for ER and IGF-1R signaling. It's the first research to demonstrate that kaempferol has anticancer action against the pro-cancer action of endogenous oestrogen and xenoestrogen in bosom cancer. It also recommends kaempferol as a major drug to modify TCS-induced malignancy hazard ${ }^{30}$. Future research should concentrate on recognizing TCScontrolled signaling molecules and their responsibility for poisonous or preventive effects of different cell types. The information obtained from such revelations will be invaluable in validating therapeutic strategies or developing potential TCS adjuvants or blockers ${ }^{209}$. In ongoing studies, animal and human growth investigations and mammalian experiments with susceptible endocrine/reproductive outcomes should be included. Systematic evaluations of these areas, particularly through deriving human health risk inferences from TCS consequences, can enable upcoming studies and regulations to safeguard people's health more efficiently ${ }^{210}$.

\section{CONCLUSION}

TCS is a synthesized antimicrobic that has been used in humans for a long time. Humans are subjected to TCS as a result of environmental and consumer good consumption. TCS exposure can cause various problems, including thyroid dysfunction, liver tumorigenesis, endocrine disruption, growth issues, muscle weakness, and oxidative stress. It is also necessary to estimate the TCS level required for tolerance choice in environmental groups. Precocious puberty and carcinogenicity could be produced by receptor overstimulation, presumably caused by the high TCS level. TCS has been linked to allergic reactions in people, according to certain research. TCS is a type 1 FAS enoyl-reductase inhibitor that has been proven to be effective in cultured cells against the MCF-7 and SK Br-3 bosom cancer cell lines. Because of its long history of human usage and ubiquitous prevalence in consumer items, as well as promising in vivo results, TCS is a viable alternative for chemotherapy.

According to extensive studies, the kaempferol anticancer effect has also been linked to the cell cycle, cell death and angiogenic, inflammatory reactions, and the formation of oxygen radicals. By adhering directly to PI3K and limiting the capacities of 
protein kinase $\mathrm{b}$ (NF- $\beta$ ) and AP-1, kaempferol suppressed the PI3K/Akt signal transduction, which affects a range of cellular activities such as growth, angiogenesis, and death. TCS's environmental survivability in sediments demonstrates that antimicrobial compounds can spread and endure breakdown mechanisms in anaerobic conditions. In addition, hydrogen peroxide speeds up the oxidation process. This system contains enzymatic and nonenzymatic antioxidants such CAT, SOD, GPx, GR, GSH, and GST. As a result, ecologists may examine the amount of oxidative stress caused in organisms exposed to specific substances by measuring antioxidant levels. The current study's lower GSH/GSSG levels might be explained because GSH could not be restored to its standard concentration in the liver after introducing TCS concentrations due to impaired GPx and GR actions.

\section{ABBREVIATIONS}

2,4-DCP: 2,4-dichlorophenol; 2,8-DCDD: 2,8dichlorodibenzo-p-dioxin; A. difformis: Anchomanes difformis; A. tumefaciens: Agrobacterium tumefaciens; APND: aminopyrine N-demethylase; AR: androgen receptor; B. subtilis: Bacillus subtilis; $\beta$-hCG: $\beta$-human chorionic gonadotropin; CAT: Catalase; COX-1: cyclooxygenase-1; CTD: chlorinated TCS derivative; D. magna: Daphnia magna; E. coli: Escherichia coli; Enoyl-ACP: acyl carrier protein; EE: ethinylestradiol; EMT: epithelial-tomesenchymal transition; ER: estrogen-receptor; ERK: extracellular signal-regulated kinase; EROD: ethoxyresorufin-O-deethylase; ERND: erythromycin $\mathrm{N}$-demethylase; FAS: enoyl-fatty acid synthesis; FSH: follicle-stimulating hormone; GAPDH: glyceraldehyde 3-phosphate dehydrogenase; GPx: Glutathione peroxidase; GR: Glutathione reductase; GSH: Glutathione; GSSG: Glutathione disulfide; GST: glutathione S-transferase; HBSS: hank's balanced salt solution; HRT: hormone replacement therapy; HS: hidradenitis suppurativa; hsp-70: heat shock protein 70 ; IL-1 $\beta$ : Interleukin- $\beta$; JNK: Jun N-terminal kinases; LFC: $\log 2$ fold change; LH: luteinizing hormone; LPO: Lipid peroxidation; LPS: lipopolysaccharides; M. smegmatis: Mycobacterium smegmatis; M. tuberculosis: Mycobacterium tuberculosis; MAPK: mitogen-activated protein kinase; MCF-7: Michigan Cancer Foundation-7; MDA: Malondialdehyde; MHC-II: Major histocompatibility complex class II; miRNA: MicroRNA; MN: micronucleus; MMP-13: matrix metalloproteinase13; NA: nuclear abnormalities; Nik: NF-B inducing kinase; NMR: nuclear magnetic resonance; $\boldsymbol{P}$. aeruginosa: Pseudomonas aeruginosa; P. falciparum: Plasmodium falciparum; PGES-1 : Prostaglandin E synthase-1 ; PGE2: prostaglandin E2; PGI2: prostaglandin I2; PI3K: phosphoinositide 3-kinase; pIRS-1: phosphorylated insulin receptor substrate-1; PKB: protein kinase B; PLA2: phospholipase A2; PTH: parathyroid hormone; R. rubrum: Rhodospirillum rubrum; ROS: Reactive oxygen species; RyR1: ryanodine receptor type 1; S. aureus: Staphylococcus aureus; S. pneumoniae: Staphylococcus pneumoniae; S. typhimurium: Salmonella typhimurium; SAM: S-adenosylmethionine; SOD: Superoxide dismutase; T. gondii: Toxoplasma gondii; T. thermopohila: Tetrahymena thermophila; TAC: Total antioxidant capacity; TCS: Triclosan; TK: thymidine kinase; TLR-4: Toll-like receptor-4; TMP: trimethoprim; TPO: thyroid peroxidase; TRPA1: Transient Receptor Potential Ankyrin 1; TSN: Testosterone; UTI: urinary tract infection; VEGF: vascular endothelial growth factor.

\section{ACKNOWLEDGMENTS}

The authors concede the support of the Cholistan University of Veterinary \& Animal SciencesBahawalpur, Pakistan, during the write-up.

\section{AUTHOR'S CONTRIBUTIONS}

Kamal Niaz: Conceptualization, outlines and editing; Furqan Shafqat, Shafeeq Ur Rehman, and Muhammad Usman: Data curation, writing- original draft preparation and drawing figures; Kamal Niaz: Supervision, reviewing and editing. All authors read and approved the final manuscript.

\section{FUNDING}

None.

\section{AVAILABILITY OF DATA AND MATERIALS}

Not applicable.

\section{ETHICS APPROVAL AND CONSENT TO PARTICIPATE}

Not applicable.

\section{CONSENT FOR PUBLICATION}

Not applicable.

\section{COMPETING INTERESTS}

The authors declare that they have no competing interests. 


\section{REFERENCES}

1. Dhillon GS, Kaur S, Pulicharla R, Brar SK, Cledón M, Verma M. Triclosan: current status, occurrence, environmental risks and bioaccumulation potential. International Journal of Environmental Research and Public Health 2015;12(5):5657-84. PMID: 26006133. Available from: 10 . 3390/ijerph120505657.

2. Hipwell $A E$, Kahn LG, Factor-Litvak P, Porucznik CA, Siegel EL, Fichorova RN, et al. Exposure to non-persistent chemicals in consumer products and fecundability: a systematic review. Human Reproduction Update. 2018;25(1):51-71. PMID: 30307509. Available from: 10.1093/humupd/dmy032.

3. Escalada MG, Harwood JL, Maillard JY, Ochs D. Triclosan inhibition of fatty acid synthesis and its effect on growth of Escherichia coli and Pseudomonas aeruginosa. The Journal of Antimicrobial Chemotherapy. 2005;55(6):879-82. PMID: 15860550. Available from: $10.1093 /$ jac/dki123.

4. Khan R, Kong HG, Jung $Y H$, Choi J, Baek KY, Hwang EC. Triclosan resistome from metagenome reveals diverse enoyl acyl carrier protein reductases and selective enrichment of triclosan resistance genes. Scientific Reports. 2016;6(1):32322. PMID: 27577999. Available from: 10.1038/ srep32322.

5. Fan C, Zhou M, Tang X, Zeng G, Xu Q, Song B. Triclosan enhances short-chain fatty acid production from sludge fermentation by elevating transcriptional activity of acidogenesis bacteria. Chemical Engineering Journal. 2020;384:123285. Available from: 10.1016/j.cej.2019.123285.

6. Latch DE, Packer JL, Stender BL, VanOverbeke J, Arnold WA, McNeill K. Aqueous photochemistry of triclosan: formation of 2,4-dichlorophenol, 2,8-dichlorodibenzo-p-dioxin, and oligomerization products. Environmental Toxicology and Chemistry. 2005;24(3):517-25. PMID: 15779749. Available from: 10.1897/04-243R.1.

7. Sánchez-Prado $L$, Llompart $M$, Lores $M$, Fernández-Alvarez M, García-Jares C, Cela R. Further research on the photoSPME of triclosan. Analytical and Bioanalytical Chemistry. 2006;384(7-8):1548-57. PMID: 16520937. Available from: 10.1007/s00216-006-0311-y.

8. Son HS, Choi SB, Zoh KD, Khan E. Effects of ultraviolet intensity and wavelength on the photolysis of triclosan. Water Science and Technology. 2007;55(1-2):209-16. PMID: 17305142. Available from: 10.2166/wst.2007.034.

9. Wang F, Xu R, Zheng F, Liu H. Effects of triclosan on acute toxicity, genetic toxicity and oxidative stress in goldfish (Carassius auratus). Experimental Animals. 2018;67(2):219-227. PMID: 29269611. Available from: 10.1538/expanim.17-0101.

10. Park JC, Han J, Lee MC, Seo JS, Lee JS. Effects of triclosan (TCS) on fecundity, the antioxidant system, and oxidative stress-mediated gene expression in the copepod Tigriopus japonicus. Aquatic Toxicology (Amsterdam, Netherlands). 2017;189:16-24. PMID: 28575748. Available from: 10.1016/j. aquatox.2017.05.012.

11. Ne A, Hm AE, Ha E, Ar M, A NE. Effect of oxymatrine on triclosan-induced ovarian toxicity in female rats. Egyptian Journal of Occupational Medicine. 2021;45(2):101-16. Available from: 10.21608/ejom.2021.170571.

12. Aliyu AB, Ibrahim MA, Musa AM, Musa AO, Kiplimo JJ, Oyewale $A O$. Free radical scavenging and total antioxidant capacity of root extracts of Anchomanes difformis Engl. (Araceae). Acta Poloniae Pharmaceutica. 2013;70(1):115-21. PMID: 23610966

13. Benzie IF, Strain JJ. The ferric reducing ability of plasma (FRAP) as a measure of antioxidant power right: the FRAP assay. Analytical Biochemistry. 1996;239(1):70-6. PMID: 8660627. Available from: 10.1006/abio.1996.0292.

14. Alfhili MA, Lee MH. Triclosan: an update on biochemical and molecular mechanisms. Oxid Med Cell Longev. 2019:2019:1607304. Available from: 10.1155/2019/1607304.

15. Mustafa $M$, Bakhiet $M$, Wondimu B, Modéer T. Effect of triclosan on interferon- $\gamma$ production and major histocompati- bility complex class II expression in human gingival fibroblasts. Journal of Clinical Periodontology. 2000;27(10):733-7. PMID: 11034119. Available from: 10.1034/j.1600-051x.2000. 027010733.x.

16. Dinwiddie MT, Terry PD, Chen J. Recent evidence regarding triclosan and cancer risk. International Journal of Environmental Research and Public Health. 2014;11(2):2209-17. PMID: 24566048. Available from: 10.3390/ijerph110202209.

17. Xue J, Wu Q, Sakthivel S, Pavithran PV, Vasukutty JR, Kannan $\mathrm{K}$. Urinary levels of endocrine-disrupting chemicals, including bisphenols, bisphenol A diglycidyl ethers, benzophenones, parabens, and triclosan in obese and non-obese Indian children. Environmental Research. 2015;137:120-8. PMID: 25531816. Available from: 10.1016/j.envres.2014.12. 007.

18. Donato MD, Cernera G, Giovannelli P, Galasso G, Bilancio A, Migliaccio A. Recent advances on bisphenol-A and endocrine disruptor effects on human prostate cancer. Molecular and Cellular Endocrinology. 2017;457:35-42. PMID: 28257827. Available from: 10.1016/j.mce.2017.02.045.

19. Kim JY, Yi BR, Go RE, Hwang KA, Nam KH, Choi KC. Methoxychlor and triclosan stimulates ovarian cancer growth by regulating cell cycle- and apoptosis-related genes via an estrogen receptor-dependent pathway. Environmental Toxicology and Pharmacology. 2014;37(3):1264-74. PMID: 24835555. Available from: 10.1016/j.etap.2014.04.013.

20. Hwang KA, Park MA, Kang NH, Yi BR, Hyun SH, Jeung EB. Anticancer effect of genistein on BG-1 ovarian cancer growth induced by $17 \beta$-estradiol or bisphenol $\mathrm{A}$ via the suppression of the crosstalk between estrogen receptor $\alpha$ and insulinlike growth factor-1 receptor signaling pathways. Toxicology and Applied Pharmacology. 2013;272(3):637-46. PMID: 23933164. Available from: 10.1016/j.taap.2013.07.027.

21. Rodricks JV, Swenberg JA, Borzelleca JF, Maronpot RR, Shipp AM. Triclosan: a critical review of the experimental data and development of margins of safety for consumer products. Critical Reviews in Toxicology. 2010;40(5):422-84. PMID: 20377306. Available from: 10.3109/10408441003667514.

22. Yueh MF, Tukey RH. Triclosan: a widespread environmental toxicant with many biological effects. Annual Review of Pharmacology and Toxicology. 2016;56(1):251-72. PMID: 26738475. Available from: 10.1146/annurev-pharmtox010715- 103417.

23. Wang C, Chen L, Zhao S, Hu Y, Zhou Y, Gao Y. Impacts of prenatal triclosan exposure on fetal reproductive hormones and its potential mechanism. Environment International. 2018;111:279-86. PMID: 29150338. Available from: 10.1016/ j.envint.2017.11.007.

24. Calafat AM, Ye X, Wong LY, Reidy JA, Needham LL. Urinary concentrations of triclosan in the U.S. population: 20032004. Environmental Health Perspectives. 2008;116(3):3037. PMID: 18335095 . Available from: 10.1289/ehp.10768.

25. Yang H, Wang W, Romano KA, Gu M, Sanidad KZ, Kim D. A common antimicrobial additive increases colonic inflammation and colitis-associated colon tumorigenesis in mice. Science Translational Medicine. 2018;10(443). PMID: 29848663. Available from: 10.1126/scitranslmed.aan4116.

26. Ahn KC, Zhao B, Chen J, Cherednichenko G, Sanmarti E, Denison MS. In vitro biologic activities of the antimicrobials triclocarban, its analogs, and triclosan in bioassay screens: receptor-based bioassay screens. Environmental Health Perspectives. 2008;116(9):1203-10. PMID: 18795164. Available from: $10.1289 /$ ehp. 11200 .

27. Nikitkova AE, Haase EM, Vickerman MM, Gill SR, Scannapieco FA. Response of fatty acid synthesis genes to the binding of human salivary amylase by Streptococcus gordonii. Applied and Environmental Microbiology. 2012;78(6):1865-75. PMID: 22247133. Available from: 10.1128/AEM.07071-11.

28. Sadowski MC, Pouwer RH, Gunter JH, Lubik AA, Quinn RJ, Nelson CC. The fatty acid synthase inhibitor triclosan: repurposing an anti-microbial agent for targeting prostate cancer. 
Oncotarget. 2014;5(19):9362-81. PMID: 25313139. Available from: 10.18632/oncotarget.2433.

29. Lee GA, Choi KC, Hwang KA. Treatment with phytoestrogens reversed triclosan and bisphenol A-induced anti-apoptosis in breast cancer cells. Biomolecules \{\&amp; \}amp; Therapeutics. 2018;26(5):503-11. PMID: 29310425. Available from: 10.4062/biomolther.2017.160.

30. Kim SH, Hwang KA, Choi KC. Treatment with kaempferol suppresses breast cancer cell growth caused by estrogen and triclosan in cellular and xenograft breast cancer models. The Journal of Nutritional Biochemistry. 2016;28:70-82. PMID: 26878784. Available from: 10.1016/j.jnutbio.2015.09.027.

31. Liu B, Wang Y, Fillgrove KL, Anderson VE. Triclosan inhibits enoyl-reductase of type I fatty acid synthase in vitro and is cytotoxic to MCF-7 and SKBr-3 breast cancer cells. Cancer Chemotherapy and Pharmacology. 2002;49(3):187-93. PMID: 11935210. Available from: 10.1007/s00280-001-0399$\mathrm{x}$.

32. Vandhana S, Coral K, Jayanthi U, Deepa PR, Krishnakumar S. Biochemical changes accompanying apoptotic cell death in retinoblastoma cancer cells treated with lipogenic enzyme inhibitors. Biochimica et Biophysica Acta. 2013;1831(9):1458-66. PMID: 23816424. Available from: 10.1016/j.bbalip.2013.06.005.

33. Henry ND, Fair PA. Comparison of in vitro cytotoxicity, estrogenicity and anti-estrogenicity of triclosan, perfluorooctane sulfonate and perfluorooctanoic acid. Journal of Applied Toxicology. 2013;33(4):265-72. PMID: 21935973. Available from: $10.1002 /$ jat.1736.

34. Dann AB, Hontela A. Triclosan: environmental exposure, toxicity and mechanisms of action. Journal of Applied Toxicology. 2011;31(4):285-311. PMID: 21462230. Available from: $10.1002 /$ jat. 1660 .

35. Deepa PR, Vandhana S, Muthukumaran S, Umashankar V, Jayanthi U, Krishnakumar S. Chemical inhibition of fatty acid synthase: molecular docking analysis and biochemical validation in ocular cancer cells. Journal of Ocular Biology, Diseases, and Informatics. 2010;3(4):117-28. PMID: 23181152. Available from: 10.1007/s12177-011-9065-7.

36. Deepa PR, Vandhana S, Jayanthi U, Krishnakumar S. Therapeutic and toxicologic evaluation of anti-lipogenic agents in cancer cells compared with non-neoplastic cells. Basic \{\&amp;\}amp; Clinical Pharmacology \{\&amp;\}amp; Toxicology. 2012;110(6):494-503. PMID: 22151915. Available from: 10.1111/j.1742-7843.2011.00844.x.

37. Rana P, Ghouse SM, Akunuri R, Madhavi YV, Chopra S, Nanduri S. Fabl (enoyl acyl carrier protein reductase) - A potential broad spectrum therapeutic target and its inhibitors. European Journal of Medicinal Chemistry. 2020;208:112757. PMID: 32883635. Available from: 10.1016/j.ejmech.2020. 112757.

38. Maiden MM, Hunt AM, Zachos MP, Gibson JA, Hurwitz ME, Mulks MH. Triclosan is an aminoglycoside adjuvant for eradication of Pseudomonas aeruginosa biofilms. Antimicrobial Agents and Chemotherapy. 2018;62(6):e00146-18. PMID: 29661867. Available from: 10.1128/AAC.00146-18.

39. Yogiara, Mordukhova EA, Kim D, Kim WG, Hwang JK, Pan JG. The food-grade antimicrobial xanthorrhizol targets the enoyl-ACP reductase (Fabl) in Escherichia coli. Bioorganic \{\&amp;\}amp; Medicinal Chemistry Letters. 2020;30(24):127651. PMID: 33130290 . Available from: 10.1016/j.bmcl.2020.127651.

40. Vosátka R, Krátký M, Vinšová J. Triclosan and its derivatives as antimycobacterial active agents. European Journal of Pharmaceutical Sciences. 2018;114:318-31. PMID: 29277667. Available from: 10.1016/j.ejps.2017.12.013.

41. Taira J, Umei T, Inoue K, Kitamura M, Berenger F, Sacchettini JC. Improvement of the novel inhibitor for Mycobacterium enoyl-acyl carrier protein reductase (InhA): a structure-activity relationship study of KES4 assisted by in silico structure-based drug screening. The Journal of Antibiotics. 2020;73(6):372-81. PMID: 32152525. Available from: 10.1038/s41429-020-0293-6.

42. Bilsland E, van Vliet L, Williams K, Feltham J, Carrasco MP, Fotoran WL. Plasmodium dihydrofolate reductase is a second enzyme target for the antimalarial action of triclosan. Scientific Reports. 2018;8(1):1038. PMID: 29348637. Available from: 10.1038/s41598-018-19549-x.

43. Rae C, Fragkoulis GI, Chalmers AJ. Cytotoxicity and radiosensitizing activity of the fatty acid synthase inhibitor $\mathrm{C} 75$ is enhanced by blocking fatty acid uptake in prostate cancer cells. Advances in Radiation Oncology. 2020;5(5):994-1005. PMID: 33083663. Available from: 10.1016/j.adro.2020.06.022.

44. Singer $H$, Müller $S$, Tixier $C$, Pillonel L. Triclosan: occurrence and fate of a widely used biocide in the aquatic environment: field measurements in wastewater treatment plants, surface waters, and lake sediments. Environmental Science \& Technology. 2002;36(23):4998-5004. PMID: 12523412. Available from: $10.1021 / \mathrm{es} 025750 \mathrm{i}$.

45. Miller TR, Heidler J, Chillrud SN, DeLaquil A, Ritchie JC, Mihalic JN, et al. Fate of triclosan and evidence for reductive dechlorination of triclocarban in estuarine sediments. Environmental Science \& Technology. 2008;42(12):4570-6. PMID: 18605588. Available from: $10.1021 / \mathrm{es} 702882 \mathrm{~g}$.

46. Hedman JE, Tocca JS, Gunnarsson JS. Remobilization of polychlorinated biphenyl from Baltic Sea sediment: comparing the roles of bioturbation and physical resuspension. Environmental Toxicology and Chemistry. 2009;28(11):2241-9. PMID: 19499969. Available from: 10.1897/08-576.1.

47. Ingerslev F, Vaclavik E, Halling-S $\varnothing$ rensen B. Pharmaceuticals and personal care products-A source of endocrine disruption in the environment? Pure and Applied Chemistry. 2003;75(11-12):1881-93. Available from: 10.1351/ pac200375111881.

48. lovino $P$, Chianese $S$, Prisciandaro M, Musmarra D. Triclosan photolysis: operating condition study and photo-oxidation pathway. Chemical Engineering Journal. 2019;377:121045. Available from: 10.1016/j.cej.2019.02.132.

49. Fiss EM, Rule KL, Vikesland PJ. Formation of chloroform and other chlorinated byproducts by chlorination of triclosancontaining antibacterial products. Environmental Science \& Technology. 2007;41(7):2387-94. PMID: 17438791. Available from: $10.1021 /$ es062227l.

50. Greyshock AE, Vikesland PJ. Triclosan reactivity in chloraminated waters. Environmental Science \& Technology. 2006;40(8):2615-22. PMID: 16683600. Available from: 10 1021/es051952d.

51. Nabeshima $Y$, Hasegawa J, Matsuda M, Kawano M, Wakimoto T, Morita M. Determination of triclosan and its related compounds in aquatic environment. Organohalogen Compounds. 2007;69:1503-6.

52. Leiker TJ, Abney SR, Goodbred SL, Rosen MR. Identification of methyl triclosan and halogenated analogues in male common carp (Cyprinus carpio) from Las Vegas Bay and semipermeable membrane devices from Las Vegas Wash, Nevada. The Science of the Total Environment. 2009;407(6):2102-14. PMID: 19054547. Available from: 10.1016/j.scitotenv.2008.11. 009.

53. Kanetoshi A, Katsura E, Ogawa H, Ohyama T, Kaneshima $\mathrm{H}_{\text {, }}$ Miura T. Acute toxicity, percutaneous absorption and effects on hepatic mixed function oxidase activities of $2,4,4$ ' trichloro-2'-hydroxydiphenyl ether (Irgasan DP300) and its chlorinated derivatives. Archives of Environmental Contamination and Toxicology. 1992;23(1):91-8. PMID: 1637203. Available from: 10.1007/BF00226000.

54. Buth JM, Grandbois M, Vikesland PJ, McNeill K, Arnold WA Aquatic photochemistry of chlorinated triclosan derivatives: potential source of polychlorodibenzo-p-dioxins. Environmental Toxicology and Chemistry. 2009;28(12):2555-63. PMID: 19908930. Available from: 10.1897/08-490.1.

55. Lee GF, Morris JC. Kinetics of chlorination of phenolchlorophenolic tastes and odors. Air and Water Pollution. 1962;6(567):419-31. PMID: 13929076. 
56. Gallard $\mathrm{H}$, von GU. Chlorination of phenols: kinetics and formation of chloroform. Environmental Science \{\&amp; \}amp; Technology. 2002;36(5):884-90. PMID: 11918011. Available from: 10.1021/es010076a.

57. Lopez-Avila V, Hites RA. Organic compounds in an industrial wastewater. Their transport into sediments. Environmental Science \{\&amp;\}amp; Technology. 1980;14(11):1382-90. Available from: 10.1021/es60171a007.

58. Meade MJ, Waddell RL, Callahan TM. Soil bacteria Pseudomonas putida and Alcaligenes xylosoxidans subsp. denitrificans inactivate triclosan in liquid and solid substrates. FEMS Microbiology Letters. 2001;204(1):45-8. PMID: 11682176. Available from: 10.1111/j.1574-6968.2001. tb10860.x.

59. Neilson AH, Allard AS, Hynning PA, Remberger M, Landner L. Bacterial methylation of chlorinated phenols and guaiacols: formation of veratroles from guaiacols and high-molecularweight chlorinated lignin. Applied and Environmental Microbiology. 1983;45(3):774-83. PMID: 16346242. Available from: 10.1128/aem.45.3.774-783.1983.

60. Field JA, Sierra-Alvarez R. Microbial degradation of chlorinated dioxins. Chemosphere. 2008;71(6):1005-18. PMID: 18083210. Available from: 10.1016/.j.chemosphere.2007.10. 039.

61. Son HS, Ko G, Zoh KD. Kinetics and mechanism of photolysis and $\mathrm{TiO} 2$ photocatalysis of triclosan. Journal of Hazardous Materials. 2009;166(2-3):954-60. PMID: 19136205. Available from: 10.1016/j.jhazmat.2008.11.107.

62. Yu JC, Kwong TY, Luo Q, Cai Z. Photocatalytic oxidation of triclosan. Chemosphere. 2006;65(3):390-9. PMID: 16571361. Available from: 10.1016/j.chemosphere.2006.02.011.

63. Coogan MA, Point TWL. Snail bioaccumulation of triclocarban, triclosan, and methyltriclosan in a North Texas, USA, stream affected by wastewater treatment plant runoff. Environmental Toxicology and Chemistry. 2008;27(8):1788-93. PMID: 18380516. Available from: 10.1897/07-374.1.

64. Boehmer W, Ruedel H, Wenzel A, Schroeter-Kermani C. Retrospective monitoring of triclosan and methyl-triclosan in fish. Results from the German Environmental Specimen Bank; 2004.

65. Wang C, Huang W, Lin J, Fang F, Wang X, Wang H. Triclosaninduced liver and brain injury in zebrafish (Danio rerio) via abnormal expression of miR-125 regulated by PKC $\alpha /$ Nrf2/p53 signaling pathways. Chemosphere. 2020;241:125086. PMID: 31627110 . Available from: 10.1016/j.chemosphere.2019.125086.

66. Liu T, Zhu L, Han Y, Wang J, Wang J, Zhao Y. The cytotoxic and genotoxic effects of metalaxy-M on earthworms (Eisenia fetida). Environmental Toxicology and Chemistry. 2014;33(10):2344-50. PMID: 25043480. Available from: $10.1002 /$ etc. 2682.

67. Gonzalez-Hunt CP, Wadhwa M, Sanders LH. DNA damage by oxidative stress: measurement strategies for two genomes. Current Opinion in Toxicology. 2018;7:87-94. Available from: 10.1016/j.cotox.2017.11.001

68. Ni H, Peng L, Gao X, Ji H, Ma J, Li Y. Effects of maduramicin on adult zebrafish (Danio rerio): acute toxicity, tissue damage and oxidative stress. Ecotoxicology and Environmental Safety. 2019;168:249-59. PMID: 30388543. Available from: 10.1016/j.ecoenv.2018.10.040.

69. Wu $M, X u H$, Shen $Y$, Qiu W, Yang M. Oxidative stress in zebrafish embryos induced by short-term exposure to bisphenol A, nonylphenol, and their mixture. Environmental Toxicology and Chemistry. 2011;30(10):2335-41. PMID: 21805498. Available from: 10.1002/etc.634.

70. Gomes MF, de Carvalho Soares de Paula V, Martins LRR, Garcia JRE, Yamamoto FY, de Freitas AM. Sublethal effects of triclosan and triclocarban at environmental concentrations in silver catfish (Rhamdia quelen) embryos. Chemosphere. 2021;263:127985. PMID: 32854011. Available from: 10.1016/ j.chemosphere.2020.127985.
71. Bao S, He C, Ku P, Xie M, Lin J, Lu S. Effects of triclosan on the RedoximiRs/Sirtuin/Nrf2/ARE signaling pathway in mosquitofish (Gambusia affinis). Aquatic Toxicology (Amsterdam, Netherlands). 2021;230:105679. PMID: 33227666. Available from: 10.1016/j.aquatox.2020.105679.

72. Maulvault AL, Camacho C, Barbosa V, Alves R, Anacleto P, Cunha SC. Bioaccumulation and ecotoxicological responses of juvenile white seabream (Diplodus sargus) exposed to triclosan, warming and acidification. Environmental Pollution. 2019;245:427-42. PMID: 30458373. Available from: 10.1016/j.envpol.2018.11.020.

73. Butterfield DA, Koppal T, Howard B, Subramaniam R, Hall N, Hensley K. Structural and functional changes in proteins induced by free radical-mediated oxidative stress and protective action of the antioxidants $\mathrm{N}$-tert-butyl- $\alpha$-phenylnitrone and vitamin E. Annals of the New York Academy of Sciences. 1998;854(1):448-62. PMID: 9928452. Available from: 10.1111/j.1749-6632.1998.tb09924.x.

74. Gyimah E, Dong X, Qiu W, Zhang Z, Xu H. Sublethal concentrations of triclosan elicited oxidative stress, DNA damage, and histological alterations in the liver and brain of adult zebrafish. Environmental Science and Pollution Research International. 2020;27(14):17329-38. PMID: 32157542. Available from: 10.1007/s11356-020-08232-2.

75. Elia AC, Galarini R, Taticchi MI, Dörr AJ, Mantilacci L. Antioxidant responses and bioaccumulation in Ictalurus melas under mercury exposure. Ecotoxicology and Environmental Safety. 2003;55(2):162-7. PMID: 12742363. Available from: 10.1016/S0147-6513(02)00123-9.

76. Freitas R, Coppola F, Costa S, Pretti C, Intorre L, Meucci V. The influence of temperature on the effects induced by Triclosan and Diclofenac in mussels. The Science of the Total Environment. 2019;663:992-9. PMID: 30771743. Available from: 10.1016/j.scitotenv.2019.01.189.

77. Sun C, Dudley S, Wang J, Gan J. Nitric oxide regulates triclosan-induced redox disequilibrium by enhancing glutathione metabolism in wheat seedlings. Environmental Science \& Technology Letters. 2019;6(5):313-7. Available from: 10.1021/acs.estlett.9b00229.

78. Oliveira R, Domingues I, Grisolia CK, Soares AM. Effects of triclosan on zebrafish early-life stages and adults. Environmental Science and Pollution Research International. 2009;16(6):679-88. PMID: 19283420. Available from: 10. 1007/s11356-009-0119-3.

79. Falisse $E$, Voisin AS, Silvestre F. Impacts of triclosan exposure on zebrafish early-life stage: toxicity and acclimation mechanisms. Aquatic Toxicology (Amsterdam, Netherlands). 2017;189:97-107. PMID: 28605648. Available from: 10.1016/ j.aquatox.2017.06.003.

80. Chen QL, Sun YL, Liu ZH, Li YW. Sex-dependent effects of subacute mercuric chloride exposure on histology, antioxidant status and immune-related gene expression in the liver of adult zebrafish (Danio rerio). Chemosphere. 2017;188:19. PMID: 28865787. Available from: 10.1016/j.chemosphere. 2017.08.148.

81. Lin D, Zhou Q, Xie X, Liu Y. Potential biochemical and genetic toxicity of triclosan as an emerging pollutant on earthworms (Eisenia fetida). Chemosphere. 2010;81(10):1328-33. PMID: 20825966. Available from: 10.1016/j.chemosphere.2010.08. 027.

82. Li C, Qu R, Chen J, Zhang S, Allam AA, Ajarem J. The pHdependent toxicity of triclosan to five aquatic organisms (Daphnia magna, Photobacterium phosphoreum, Danio rerio, Limnodrilus hoffmeisteri, and Carassius auratus). Environmental Science and Pollution Research International. 2018;25(10):9636-46. PMID: 29363032. Available from: 10.1007/s11356-018-1284-z.

83. Peng $Y$, Luo $Y$, Nie $X P$, Liao $W$, Yang $Y F$, Ying GG. Toxic effects of triclosan on the detoxification system and breeding of Daphnia magna. Ecotoxicology (London, England). 2013;22(9):1384-94. PMID: 24022518. Available from: 10. 1007/s10646-013-1124-3. 
84. Kovacevic V, Simpson AJ, Simpson MJ. (1)H NMR-based metabolomics of Daphnia magna responses after sublethal exposure to triclosan, carbamazepine and ibuprofen. Comparative Biochemistry and Physiology Part D, Genomics \{\&amp; \}amp; Proteomics. 2016;19:199-210. PMID: 26809854. Available from: 10.1016/j.cbd.2016.01.004.

85. Riva C, Cristoni S, Binelli A. Effects of triclosan in the freshwater mussel Dreissena polymorpha: a proteomic investigation. Aquatic Toxicology (Amsterdam, Netherlands). 2012;118-119:62-71. PMID: 22522169. Available from: 10. 1016/j.aquatox.2012.03.013.

86. Ku P, Wu X, Nie X, Ou R, Wang L, Su T, et al. Effects of triclosan on the detoxification system in the yellow catfish (Pelteobagrus fulvidraco): expressions of CYP and GST genes and corresponding enzyme activity in phase I, II and antioxidant system. Comparative Biochemistry and Physiology Toxicology \& Pharmacology : CBP. 2014;166:105-14. PMID: 25064140. Available from: 10.1016/j.cbpc.2014.07.006.

87. Banerjee P, Dey TK, Sarkar S, Swarnakar S, Mukhopadhyay A, Ghosh S. Treatment of cosmetic effluent in different configurations of ceramic UF membrane based bioreactor: toxicity evaluation of the untreated and treated wastewater using catfish (Heteropneustes fossilis). Chemosphere. 2016;146:133-44. PMID: 26714296. Available from: 10.1016/ j.chemosphere.2015.12.004.

88. Pirone G, Coppola F, Pretti C, Soares AM, Solé M, Freitas R The effect of temperature on Triclosan and Lead exposed mussels. Comparative Biochemistry and Physiology Part B Biochemistry \& Molecular Biology. 2019;232:42-50. PMID: 30807847. Available from: 10.1016/j.cbpb.2019.02.007.

89. Berger K, Gunier RB, Chevrier J, Calafat AM, Ye X, Eskenazi $B$. Associations of maternal exposure to triclosan parabens, and other phenols with prenatal maternal and neonatal thyroid hormone levels. Environmental Research. 2018;165:379-86. PMID: 29803919. Available from: 10.1016/ j.envres.2018.05.005.

90. Ak T, Gülçin I. Antioxidant and radical scavenging properties of curcumin. Chemico-Biological Interactions. 2008;174(1):27-37. PMID: 18547552. Available from: 10 1016/j.cbi.2008.05.003

91. Garcia, Ashley Marie, "Effect of Triclosan-Tolerant Plant Growth-Promoting Rhizobacteria on Triclosan Degradation in Soils" (2020). Theses and Dissertations. 113. https://rio.ta miu.edu/etds/113.

92. Aderogba $M$, Okoh E, Idowu T, Aderogba MA, Okoh EK, Idowu TO. Evaluation of the antioxidant activity of the secondary metabolites from Piliostigma reticulatum (DC.) Hochst. Journal of Biological Sciences (Faisalabad, Pakistan). 2005;5(2):239-42. Available from: 10.3923/jbs.2005.239.242.

93. Kähkönen MP, Hopia Al, Vuorela HJ, Rauha JP, Pihlaja K, Kujala TS. Antioxidant activity of plant extracts containing phenolic compounds. Journal of Agricultural and Food Chemistry. 1999;47(10):3954-62. PMID: 10552749. Available from: $10.1021 /$ jf9901461

94. Horie $\mathrm{Y}$, Yamagishi $\mathrm{T}$, Takahashi $\mathrm{H}$, Iguchi T, Tatarazako N. Effects of triclosan on Japanese medaka (Oryzias latipes) during embryo development, early life stage and reproduction. Journal of Applied Toxicology. 2018;38(4):544-51. PMID: 29181881. Available from: 10.1002/jat.3561.

95. Cho EJ, Yokozawa T, Rhyu DY, Kim SC, Shibahara N, Park JC. Study on the inhibitory effects of Korean medicinal plants and their main compounds on the 1,1-diphenyl-2-picrylhydrazyl radical. Phytomedicine. 2003;10(6-7):544-51. PMID: 13678241. Available from: 10.1078/094471103322331520.

96. Regös J, Zak O, Solf R, Vischer WA, Weirich EG. Antimicrobia spectrum of triclosan, a broad-spectrum antimicrobial agent for topical application. II. Comparison with some other antimicrobial agents. Dermatologica. 1979;158(1):72-9. PMID: 761692. Available from: 10.1159/000250746.

97. Regös J, Hitz HR. Investigations on the mode of action of Triclosan, a broad spectrum antimicrobial agent. Zen- tralblatt f\{\&amp; $\}\{\#\} \times 00 F C ; r$ Bakteriologie, Parasitenkunde, Infektionskrankheiten und Hygiene Erste Abteilung Originale Reihe A: Medizinische Mikrobiologie und Parasitologie. 1974;226(3):390-401. PMID: 4151803.

98. Betts JC, McLaren A, Lennon MG, Kelly FM, Lukey PT, Blakemore SJ. Signature gene expression profiles discriminate between isoniazid-, thiolactomycin-, and triclosan-treated Mycobacterium tuberculosis. Antimicrobial Agents and Chemotherapy. 2003;47(9):2903-13. PMID: 12936993. Available from: 10.1128/AAC.47.9.2903-2913.2003.

99. Srinivasan VB, Singh BB, Priyadarshi N, Chauhan NK, Rajamohan $\mathrm{G}$. Role of novel multidrug efflux pump involved in drug resistance in Klebsiella pneumoniae. PLoS One. 2014;9(5):e96288. PMID: 24823362. Available from: 10.1371/ journal.pone.0096288.

100. McMurry LM, Oethinger M, Levy SB. Overexpression of marA soxS, or acrAB produces resistance to triclosan in laboratory and clinical strains of Escherichia coli. FEMS Microbiology Letters. 1998;166(2):305-9. PMID: 9770288. Available from: 10.1111/j.1574-6968.1998.tb13905.x.

101. Miller TL, Deinzer ML. Effects of nonachloropredioxin and other hydroxychlorodiphenyl ethers on biological membranes. Journal of Toxicology and Environmental Health. 1980;6(1):11-25. PMID: 7381964. Available from: 10.1080/ 15287398009529827.

102. Villalaín J, Mateo CR, Aranda FJ, Shapiro S, Micol V. Membranotropic effects of the antibacterial agent Triclosan. Archives of Biochemistry and Biophysics. 2001;390(1):128-36. PMID: 11368524. Available from: 10.1006/abbi.2001.2356.

103. Guillén J, Bernabeu A, Shapiro S, Villalaín J. Location and orientation of Triclosan in phospholipid model membranes. European Biophysics Journal. 2004;33(5):448-53. PMID: 14714154. Available from: 10.1007/s00249-003-0378-8.

104. Honkisz E, Zieba-Przybylska D, Wojtowicz AK. The effect of triclosan on hormone secretion and viability of human choriocarcinoma JEG-3 cells. Reproductive Toxicology (Elmsford, NY). 2012;34(3):385-92. PMID: 22677473. Available from: 10.1016/j.reprotox.2012.05.094.

105. Winitthana T, Lawanprasert S, Chanvorachote P. Triclosan potentiates epithelial-to-mesenchymal transition in anoikis-resistant human lung cancer cells. PLoS One. 2014;9(10):e110851. PMID: 25329306. Available from: 10. 1371/journal.pone.0110851.

106. Kim YS, Seo HW, Lee MH, Kim DK, Jeon H, Cha DS. Protocatechuic acid extends lifespan and increases stress resistance in Caenorhabditis elegans. Archives of Pharmacal Research. 2014;37(2):245-52. PMID: 23780797. Available from: 10.1007/s12272-013-0183-6

107. Shin MK, Jeon YD, Hong SH, Kang SH, Kee JY, Jin JS. In Vivo and In Vitro Effects of Tracheloside on Colorectal Cancer Cell Proliferation and Metastasis. Antioxidants. 2021;10(4):513. PMID: 33806109 . Available from: 10.3390/antiox10040513.

108. Farasani A, Darbre PD. Long-term exposure to triclosan increases migration and invasion of human breast epithelial cells in vitro. Journal of Applied Toxicology. 2021;41(7):111526. PMID: 33171535. Available from: 10.1002/jat.4097.

109. Lee HR, Hwang KA, Nam KH, Kim HC, Choi KC. Progression of breast cancer cells was enhanced by endocrinedisrupting chemicals, triclosan and octylphenol, via an estrogen receptor-dependent signaling pathway in cellular and mouse xenograft models. Chemical Research in Toxicology. 2014;27(5):834-42. PMID: 24684733. Available from: $10.1021 /$ tx5000156

110. Aliaga A, Castells A, Kriznik D, Lalosević J, Marrón J, Moragas J. An overview of two comparative multicentre trials with halometasone/triclosan cream in acute superficial bacterial skin infections. The Journal of International Medical Research. 1983;11:53-7. PMID: 6339294.

111. Huber $\mathrm{L}$. Role of Klion ointment in the treatment of crural ulcer. Therapia Hungarica (English Edition). 1991;39(3):148150. PMID: 1818430 . Available from: https://europepmc.org/ 
article/med/1818430.

112. Culić O, Eraković V, Parnham MJ. Anti-inflammatory effects of macrolide antibiotics. European Journal of Pharmacology. 2001;429(1-3):209-29. PMID: 11698042. Available from: 10. 1016/S0014-2999(01)01321-8.

113. Gaffar A, Scherl D, Afflitto J, Coleman EJ. The effect of triclosan on mediators of gingival inflammation. Journal of Clinical Periodontology. 1995;22(6):480-4. PMID: 7560228. Available from: 10.1111/j.1600-051X.1995.tb00181.x.

114. Modéer T, Bengtsson A, Rölla G. Triclosan reduces prostaglandin biosynthesis in human gingival fibroblasts challenged with interleukin-1 in vitro. Journal of Clinical Periodontology. 1996;23(10):927-33. PMID: 8915021. Available from: 10.1111/j.1600-051X.1996.tb00513.x.

115. Skaare AB, Rölla G, Barkvoll P. The influence of triclosan, zinc or propylene glycol on oral mucosa exposed to sodium lauryl sulphate. European Journal of Oral Sciences. 1997;105(5 Pt 2):527-33. PMID: 9395119. Available from: $10.1111 / j .1600-$ 0722.1997.tb00240.x.

116. Mustafa M, Wondimu B, Hultenby K, Yucel-Lindberg T, Modéer T. Uptake, distribution and release of 14C-triclosan in human gingival fibroblasts. Journal of Pharmaceutical Sciences. 2003;92(8):1648-53. PMID: 12884251. Available from: $10.1002 /$ jps.10429.

117. Wallet MA, Calderon N, Alonso TR, Choe CS, Catalfamo $D$ Lalane CJ. Triclosan alters antimicrobial and inflammatory responses of epithelial cells. Oral Diseases. 2013;19(3):296302. PMID: 24079913. Available from: 10.1111/odi.12001

118. Neiva KG, Calderon NL, Alonso TR, Panagakos F, Wallet SM. Type 1 diabetes-associated TLR responsiveness of oral epithelial cells. Journal of Dental Research. 2014;93(2):169-74. PMID: 24334435. Available from: 10. $1177 / 0022034513516345$.

119. Marshall NB, Lukomska E, Nayak AP, Long CM, Hettick JM, Anderson SE. Topical application of the anti-microbial chemical triclosan induces immunomodulatory responses through the S100A8/A9-TLR4 pathway. Journal of Immunotoxicology. 2017;14(1):50-9. PMID: 28121465. Available from: 10.1080/1547691X.2016.1258094.

120. Barnes VM, Xu T, Shimizu E, Nakatani T, Jefcoat S, Vasilov A. Triclosan blocks MMP-13 expression in hormone-stimulated osteoblasts. Journal of Periodontology. 2013;84(11):1683-9. PMID: 23368947.

121. Pancer BA, Kott D, Sugai JV, Panagakos FS, Braun TM, Teles RP. Effects of triclosan on host response and microbial biomarkers during experimental gingivitis. Journal of Clinical Periodontology. 2016;43(5):435-44. PMID: 26820239. Available from: $10.1111 /$ jcpe.12519.

122. Watkins DJ, Ferguson KK, Toro LVAD, Alshawabkeh AN, Cordero JF, Meeker JD. Associations between urinary phenol and paraben concentrations and markers of oxidative stress and inflammation among pregnant women in Puerto Rico. International Journal of Hygiene and Environmental Health. 2015;218(2):212-9. PMID: 25435060. Available from: 10.1016/j.ijheh.2014.11.001.

123. Uings IJ, Farrow SN. Cell receptors and cell signalling. Molecular Pathology. 2000;53(6):295-9. PMID: 11193047. Available from: $10.1136 / \mathrm{mp} \cdot 53.6 .295$.

124. Wu Y, Beland FA, Chen S, Fang JL. Extracellular signalregulated kinases $1 / 2$ and Akt contribute to triclosanstimulated proliferation of JB6 Cl 41-5a cells. Archives of Toxicology. 2015;89(8):1297-311. PMID: 25033989. Available from: 10.1007/s00204-014-1308-5.

125. Dubey D, Srivastav AK, Singh J, Chopra D, Qureshi S, Kushwaha HN. Photoexcited triclosan induced DNA damage and oxidative stress via p38 MAP kinase signaling involving type I radicals under sunlight/UVB exposure. Ecotoxicology and Environmental Safety. 2019;174:270-82. PMID: 30844667. Available from: 10.1016/j.ecoenv.2019.02.065.

126. Park BK, Gonzales EL, Yang SM, Bang M, Choi CS, Shin CY. Effects of triclosan on neural stem cell viability and survival. Biomolecules \{\&amp; $\} a m p ;$ Therapeutics.
2016;24(1):99-107. PMID: 26759708. Available from: 10 . 4062/biomolther.2015.164.

127. Zhang $P$, Yang $M$, Zeng L, Liu C. P38/TRHr-dependent regulation of TPO in thyroid cells contributes to the hypothyroidism of triclosan-treated rats. Cellular Physiology and Biochemistry. 2018;45(4):1303-15. PMID: 29462796. Available from: $10.1159 / 000487558$

128. Barros SP, Wirojchanasak S, Barrow DA, Panagakos FS, Devizio $\mathrm{W}$, Offenbacher $\mathrm{S}$. Triclosan inhibition of acute and chronic inflammatory gene pathways. Journal of Clinical Periodontology. 2010;37(5):412-8. PMID: 20507366. Available from: 10.1111/j.1600-051X.2010.01548.x.

129. Huang H, Du G, Zhang W, Hu J, Wu D, Song L. The in vitro estrogenic activities of triclosan and triclocarban. Journal of Applied Toxicology. 2014;34(9):1060-7. PMID: 24740835. Available from: 10.1002/jat.3012.

130. Stoker TE, Gibson EK, Zorrilla LM. Triclosan exposure modulates estrogen-dependent responses in the female wistar rat. Toxicological Sciences. 2010;117(1):45-53. PMID: 20562219. Available from: 10.1093/toxsci/kfq180.

131. James MO, Li W, Summerlot DP, Rowland-Faux L, Wood CE. Triclosan is a potent inhibitor of estradiol and estrone sulfonation in sheep placenta. Environment International. 2010;36(8):942-9. PMID: 19299018. Available from: 10.1016/ j.envint.2009.02.004.

132. Liu J, Sun L, Zhang H, Shi M, Dahlgren RA, Wang X. Response mechanisms to joint exposure of triclosan and its chlorinated derivatives on zebrafish (Danio rerio) behavior. Chemosphere. 2018;193:820-32. PMID: 29874755. Available from: 10.1016/j.chemosphere.2017.11.106.

133. Chen J, Ahn KC, Gee NA, Gee SJ, Hammock BD, Lasley BL. Antiandrogenic properties of parabens and other phenolic containing small molecules in personal care products. Toxicology and Applied Pharmacology. 2007;221(3):278-84. PMID: 17481686. Available from: 10.1016/j.taap.2007.03.015.

134. Riad MA, Abd-Rabo MM, Aziz SAAE, Behairy AME, Badawy MM. Reproductive toxic impact of subchronic treatment with combined butylparaben and triclosan in weanling male rats. Journal of Biochemical and Molecular Toxicology. 2018;32(3):e22037. PMID: 29350491. Available from: 10. $1002 /$ jbt.22037.

135. Clapham DE. Calcium signaling. Cell. 2007;131(6):1047-58. PMID: 18083096. Available from: 10.1016/j.cell.2007.11.028.

136. Cherednichenko G, Zhang R, Bannister RA, Timofeyev V, Li $\mathrm{N}$, Fritsch EB. Triclosan impairs excitation-contraction coupling and $\mathrm{Ca} 2+$ dynamics in striated muscle. Proceedings of the National Academy of Sciences of the United States of America. 2012;109(35):14158-63. PMID:22891308. Available from: $10.1073 /$ pnas.1211314109.

137. Fritsch EB, Connon RE, Werner I, Davies RE, Beggel S, Feng W et al. Triclosan impairs swimming behavior and alters expression of excitation-contraction coupling proteins in fathead minnow (Pimephales promelas). Environmental Science \& Technology. 2013;47(4):2008-17. PMID: 23305567. Available from: $10.1021 / \mathrm{es} 303790 \mathrm{~b}$

138. Li SJ, Chen P, Peres TV, Villahoz BF, Zhang Z, Miah MR. Triclosan induces PC12 cells injury is accompanied by inhibition of AKT/mTOR and activation of p38 pathway. Neurotoxicology. 2019;74:221-9. PMID: 31381933. Available from: 10.1016/j.neuro.2019.07.008.

139. Hussien NA, Hamdi H. Genotoxic and hypogonadism effect of triclosan treatment and the mitigating effect of vitamin $\mathrm{e}$ in male albino mice. International Journal of Clinical Pharmacy. 2017;8(4).

140. Olaniyan LW, Mkwetshana N, Okoh Al. Triclosan in water, implications for human and environmental health. SpringerPlus. 2016;5(1):1639. PMID: 27722057. Available from: 10. 1186/s40064-016-3287-x.

141. Wang $C$, Li Y, Zheng G, Zhang S, Wan Y, Hu J. Adverse effects of triclosan and binary mixtures with $17 \beta$-estradiol on testicular development and reproduction in Japanese medaka 
(Oryzias latipes) at environmentally relevant concentrations. Environmental Science \& Technology Letters. 2018;5(3):13641. Available from: $10.1021 /$ acs.estlett.8b00003.

142. Muller D, Nelles J, Deparade E, Arni P. Studies of the activity of S9-liver fractions from various species in the Ames test. Mutation Research - Environmental Mutagenesis and Related Subjets. 1979;64(2):104-5. Available from: 10.1016/ 0165-1161(79)90011-6.

143. Wang Z, Li X, Klaunig JE. Investigation of the mechanism of triclosan induced mouse liver tumors. Regulatory Toxicology and Pharmacology. 2017;86:137-47. PMID: 28267557. Available from: 10.1016/j.yrtph.2017.03.001.

144. Strasser F, Müller D. Chromosome Studies on Somatic CellsGP 41353 (Triclosan). Chinese Hamster. Ciba-Geigy Ltd.; 1973.

145. Müller D, Strasser FF, Röhrborn G, Fränz J, Grafe A, Mittenburger HG. Chromosome analysis of bone marrow in mammals after treatment with isoniazid. Human Genetics. 1978;42(1):15-25. PMID: 649162. Available from: 10.1007/ BF00291618.

146. DeSalva SJ, Kong BM, Lin YJ. Triclosan: a safety profile. American Journal of Dentistry. 1989;2(Spec No):185-96. PMID: 2638179.

147. Bhargava HN, Leonard PA. Triclosan: applications and safety. American Journal of Infection Control. 1996;24(3):209-18. PMID: 8807001. Available from: 10.1016/S0196-6553(96) 90017-6.

148. Fahrig R, Nilsson CA, Rappe C. Genetic activity of chlorophenols and chlorophenol impurities. Pentachlorophenol. Springer; 1978.

149. Russell LB, Montgomery CS. Use of the mouse spot test to investigate the mutagenic potential of triclosan (Irgasan DP300). Mutation Research. 1980;79(1):7-12. PMID: 7432367. Available from: 10.1016/0165-1218(80)90142-1.

150. Heath RJ, Rubin JR, Holland DR, Zhang E, Snow ME, Rock CO. Mechanism of triclosan inhibition of bacterial fatty acid synthesis. The Journal of Biological Chemistry. 1999;274(16):11110-4. PMID: 10196195. Available from: 10.1074/jbc.274.16.11110.

151. Sivaraman S, Zwahlen J, Bell AF, Hedstrom L, Tonge PJ. Structure-activity studies of the inhibition of Fabl, the enoy reductase from Escherichia coli, by triclosan: kinetic analysis of mutant Fabls. Biochemistry. 2003;42(15):4406-13. PMID: 12693936. Available from: 10.1021/bi0300229.

152. Lu J, Jin M, Nguyen SH, Mao L, Li J, Coin LJ. Non-antibiotic antimicrobial triclosan induces multiple antibiotic resistance through genetic mutation. Environment International. 2018;118:257-65. PMID: 29902774. Available from: 10.1016/ j.envint.2018.06.004.

153. Yasir M, Turner AK, Bastkowski S, Page AJ, Telatin A, Phan $M D$, et al. A new massively-parallel transposon mutagenesis approach comparing multiple datasets identifies novel mechanisms of action and resistance to triclosan. bioRxiv. 2019;2019. Available from: 10.1101/596833.

154. Grundström T, Jaurin B. Overlap between ampC and frd operons on the Escherichia coli chromosome. Proceedings of the National Academy of Sciences of the United States of America. 1982;79(4):1111-5. PMID: 7041115. Available from: 10.1073/pnas.79.4.1111.

155. Tracz DM, Boyd DA, Bryden L, Hizon R, Giercke S, Caeseele $\mathrm{PV}$. Increase in ampC promoter strength due to mutations and deletion of the attenuator in a clinical isolate of cefoxitinresistant Escherichia coli as determined by RT-PCR. The Journal of Antimicrobial Chemotherapy. 2005;55(5):768-72. PMID: 15761065. Available from: 10.1093/jac/dki074.

156. Castellanos LR, Donado-Godoy $P$, León M, Clavijo V, Arevalo $A$, Bernal JF. High heterogeneity of Escherichia coli sequence types harbouring ESBL/AmpC genes on Incl1 plasmids in the Colombian poultry chain. PLoS One. 2017;12(1):e0170777. PMID: 28125687. Available from: 10.1371/journal.pone. 0170777 .
157. Koutsolioutsou A, Peña-Llopis S, Demple B. Constitutive soxR mutations contribute to multiple-antibiotic resistance in clinical Escherichia coli isolates. Antimicrobial Agents and Chemotherapy. 2005;49(7):2746-52. PMID: 15980345. Available from: 10.1128/AAC.49.7.2746-2752.2005.

158. White DG, Goldman JD, Demple B, Levy SB. Role of the acrAB locus in organic solvent tolerance mediated by expression of marA, soxS, or robA in Escherichia coli. Journal of Bacteriology. 1997;179(19):6122-6. PMID: 9324261. Available from: 10.1128/jb.179.19.6122-6126.1997.

159. Liu Y, Li R, Xiao X, Wang Z. Antibiotic adjuvants: an alternative approach to overcome multi-drug resistant Gram-negative bacteria. Critical Reviews in Microbiology. 2019;45(3):30114. PMID: 30985240. Available from: 10.1080/1040841X.2019. 1599813.

160. Bhandol HJ, Alindogan J, de Guzman A, Lim R. Structure and regulation of the Acr efflux pumps and their role in antibiotic resistance in Escherichia coli. Undergraduate J Exp Microbiol Immunol. 2020;6:1-16.

161. Duarte NA, de Lima LE, Maraslis FT, Kundi M, Nunes EA, Barcelos GR. Acute toxicity and DNA instability induced by exposure to low doses of triclosan and phthalate DEHP, and their combinations, in vitro. Frontiers in Genetics, 2021;12:649845. PMID: 33959150. Available from: 10.3389/ fgene.2021.649845.

162. Sun L, Gao M, Qian Q, Guo Z, Zhu P, Wang X. Triclosaninduced abnormal expression of miR-30b regulates ftomediated m6A methylation level to cause lipid metabolism disorder in zebrafish. The Science of the Total Environment. 2021;770:145285. PMID: 33515893. Available from: 10.1016/ j.scitotenv.2021.145285.

163. Schena D, Papagrigoraki A, Girolomoni G. Sensitizing potential of triclosan and triclosan-based skin care products in patients with chronic eczema. Dermatologic Therapy. 2008;21:35-8. PMID: 18837732. Available from: 10.1111/j. 1529-8019.2008.00231.x.

164. Robertshaw H, Leppard B. Contact dermatitis to triclosan in toothpaste. Contact Dermatitis. 2007;57(6):383-4. PMID: 17988290. Available from: 10.1111/j.0105-1873.2005.00771. $\mathrm{x}$.

165. Spanier AJ, Fausnight T, Camacho TF, Braun JM, editors. The associations of triclosan and paraben exposure with allergen sensitization and wheeze in children. Allergy Asthma Proc; 2014: OceanSide Publications.

166. Chen Y, Fang J, Ren L, Fan R, Zhang J, Liu G. Urinary bisphenol analogues and triclosan in children from south China and implications for human exposure. Environmental Pollution. 2018;238:299-305. PMID: 29573712. Available from: 10.1016/j.envpol.2018.03.031.

167. Roy JR, Chakraborty S, Chakraborty TR. Estrogen-like endocrine disrupting chemicals affecting puberty in humans review. Medical Science Monitor. 2009;15(6):137-45. PMID: 19478717.

168. Darbre PD. Environmental oestrogens, cosmetics and breast cancer. Best Practice \& Research Clinical Endocrinology \& Metabolism. 2006;20(1):121-43. PMID: 16522524. Available from: 10.1016/j.beem.2005.09.007.

169. Wilson AS, Power BE, Molloy PL. DNA hypomethylation and human diseases. Biochimica et Biophysica Acta. 2007;1775(1):138-62. PMID: 17045745.

170. Gee RH, Charles A, Taylor N, Darbre PD. Oestrogenic and androgenic activity of triclosan in breast cancer cells. Journal of Applied Toxicology. 2008;28(1):78-91. PMID: 17992702. Available from: 10.1002/jat.1316.

171. Bertelsen RJ, Longnecker MP, Løvik M, Calafat AM, Carlsen $\mathrm{KH}$, London SJ. Triclosan exposure and allergic sensitization in Norwegian children. Allergy. 2013;68(1):84-91. PMID: 23146048. Available from: 10.1111/all.12058.

172. Lin Z, Zhang X, Zhao F, Ru S. Bisphenol S promotes the cell cycle progression and cell proliferation through ER $\alpha$-cyclin D-CDK4/6-pRb pathway in MCF-7 breast cancer cells. Toxicology and Applied Pharmacology. 2019;366:75-82. PMID: 
30684532. Available from: 10.1016/j.taap.2019.01.017.

173. Dayan AD. Risk assessment of triclosan [Irgasan] in human breast milk. Food and Chemical Toxicology. 2007;45(1):1259. PMID: 17011099 . Available from: 10.1016/j.fct.2006.08.009.

174. Veldhoen N, Skirrow RC, Osachoff $\mathrm{H}$, Wigmore $\mathrm{H}$, Clapson DJ, Gunderson MP. The bactericidal agent triclosan modulates thyroid hormone-associated gene expression and disrupts postembryonic anuran development. Aquatic Toxicology (Amsterdam, Netherlands). 2006;80(3):217-27. PMID: 17011055. Available from: 10.1016/j.aquatox.2006.08.010

175. Koeppe ES, Ferguson KK, Colacino JA, Meeker JD. Relationship between urinary triclosan and paraben concentrations and serum thyroid measures in NHANES 2007-2008. The Science of the Total Environment. 2013;445-446:299-305. PMID: 23340023. Available from: 10.1016/j.scitotenv.2012.12. 052.

176. Heublein S, Mayr D, Meindl A, Angele M, Gallwas J, Jeschke $U$. Thyroid hormone receptors predict prognosis in BRCA1 associated breast cancer in opposing ways. PLoS One. 2015;10(6):e0127072. PMID: 26029931. Available from: 10.1371/journal.pone.0127072.

177. Badv M, Bayat F, Weitz Jl, Didar TF. Single and multifunctional coating strategies for enhancing the biocompatibility and tissue integration of blood-contacting medical implants. Biomaterials. 2020;258:120291. PMID: 32798745. Available from: 10.1016/j.biomaterials.2020.120291.

178. Derouiche $S$, Mariot $P$, Warnier M, Vancauwenberghe $E$, Bidaux G, Gosset P. Activation of TRPA1 channel by antibacterial agent triclosan induces VEGF secretion in human prostate cancer stromal cells. Cancer Prevention Research (Philadelphia, Pa). 2017;10(3):177-87. PMID: 28096238. Available from: 10.1158/1940-6207.CAPR-16-0257.

179. Cunha GR, Hayward SW, Wang YZ. Role of stroma in carcinogenesis of the prostate. Differentiation. 2002;70(9-10):47385. PMID: 12492490. Available from: 10.1046/j.1432-0436. 2002.700902.x.

180. Guo Z, Yang X, Sun F, Jiang R, Linn DE, Chen H. A novel androgen receptor splice variant is up-regulated during prostate cancer progression and promotes androgen depletionresistant growth. Cancer Research. 2009;69(6):2305-13. PMID: 19244107. Available from: 10.1158/0008-5472.CAN08-3795.

181. Jankevicius F, Miller SM, Ackermann R. Nutrition and risk of prostate cancer. Urologia Internationalis. 2002;68(2):69-80. PMID: 11834894 . Available from: 10.1159/000048422.

182. Liotta LA, Kohn EC. The microenvironment of the tumourhost interface. Nature. 2001;411(6835):375-9. PMID: 11357145. Available from: 10.1038/35077241.

183. Gao L, Yuan T, Cheng P, Bai Q, Zhou C, Ao J. Effects of triclosan and triclocarban on the growth inhibition, cell viability, genotoxicity and multixenobiotic resistance responses of Tetrahymena thermophila. Chemosphere. 2015;139:43440. PMID: 26246462. Available from: 10.1016/j.chemosphere. 2015.07.059.

184. Sethuraman S, Kumar TR. Triclosan induced genotoxic effect on zebra fish, brachydanio rerio by using alkaline comet assay. Int J Modn Res Revs. 2014;2(11):473-7.

185. Wang F, Zheng F, Liu F. Effects of triclosan on antioxidantand apoptosis-related genes expression in the gill and ovary of zebrafish. Experimental Animals. 2019;69(2):199-206. Available from: 10.1538/expanim.19-0115.

186. Binelli A, Cogni D, Parolini M, Riva C, Provini A. Cytotoxic and genotoxic effects of in vitro exposure to triclosan and trimethoprim on zebra mussel (Dreissena polymorpha) hemocytes. Comparative Biochemistry and Physiology Toxicology \{\&amp;\}amp; Pharmacology : CBP. 2009;150(1):50-6. PMID: 19232398. Available from: 10.1016/j.cbpc.2009.02.005.

187. Ciniglia C, Cascone C, Giudice RL, Pinto G, Pollio A. Application of methods for assessing the geno- and cytotoxicity of Triclosan to C. ehrenbergii. Journal of Hazardous Materials. 2005:122(3):227-32. PMID: 15967278. Available from: 10.1016/j.jhazmat.2005.03.002.
188. Yueh MF, Taniguchi K, Chen S, Evans RM, Hammock BD, Karin M. The commonly used antimicrobial additive triclosan is a liver tumor promoter. Proceedings of the $\mathrm{Na}$ tional Academy of Sciences of the United States of America. 2014;111(48):17200-5. PMID: 25404284. Available from: 10.1073/pnas.1419119111.

189. Cavas T, Garanko NN, Arkhipchuk VV. Induction of micronuclei and binuclei in blood, gill and liver cells of fishes subchronically exposed to cadmium chloride and copper sulphate. Food and Chemical Toxicology. 2005;43(4):569-74. PMID: 15721204. Available from: 10.1016/j.fct.2004.12.014.

190. Cavaş T, Ergene-Gözükara S. Induction of micronuclei and nuclear abnormalities in Oreochromis niloticus following exposure to petroleum refinery and chromium processing plant effluents. Aquatic Toxicology (Amsterdam, Netherlands). 2005;74(3):264-71. PMID: 16023743. Available from: 10.1016/j.aquatox.2005.06.001.

191. Xu X, Lu Y, Zhang D, Wang Y, Zhou X, Xu H. Toxic assessment of triclosan and triclocarban on Artemia salina. Bulletin of Environmental Contamination and Toxicology. 2015;95(6):728-33. PMID: 26310128. Available from: 10. 1007/s00128-015-1641-2.

192. Kim SH, Choi KC. Anti-cancer effect and underlying mechanism (s) of kaempferol, a phytoestrogen, on the regulation of apoptosis in diverse cancer cell models. Toxicological Research. 2013;29(4):229-34. PMID: 24578792. Available from: 10.5487/TR.2013.29.4.229.

193. Danial NN, Korsmeyer SJ. Cell death: critical control points. Cell. 2004;116(2):205-19. PMID: 14744432. Available from: 10.1016/S0092-8674(04)00046-7.

194. Klein G, Klein E. Immune surveillance against virus-induced tumors and nonrejectability of spontaneous tumors: contrasting consequences of host versus tumor evolution. Proceedings of the National Academy of Sciences of the United States of America. 1977;74(5):2121-5. PMID: 194247. Available from: 10.1073/pnas.74.5.2121.

195. McDonnell G, Russell AD. Antiseptics and disinfectants: ac tivity, action, and resistance. Clinical Microbiology Reviews. 2001;14(1):227. PMID: 9880479. Available from: 10.1128/ CMR.14.1.227-227.2001.

196. Pizer ES, Jackisch C, Wood FD, Pasternack GR, Davidson NE Kuhajda FP. Inhibition of fatty acid synthesis induces programmed cell death in human breast cancer cells. Cancer Research. 1996;56(12):2745-7. PMID: 8665507.

197. Wilentz RE, Witters LA, Pizer ES. Lipogenic enzymes fatty acid synthase and acetyl-coenzyme A carboxylase are coexpressed with sterol regulatory element binding protein and Ki-67 in fetal tissues. Pediatric and Developmental Pathology. 2000;3(6):525-31. PMID: 11000330. Available from: $10.1007 / \mathrm{s} 100240010116$.

198. Branca F, Lorenzetti S. Health effects of phytoestrogens. Forum of Nutrition. 2005;57(57):100-11. PMID: 15702593. Available from: 10.1159/000083773.

199. Ren W, Qiao Z, Wang H, Zhu L, Zhang L. Flavonoids: promising anticancer agents. Medicinal Research Reviews. 2003;23(4):519-34. PMID: 12710022. Available from: 10. 1002/med.10033.

200. Adlercreutz H, Mousavi Y, Clark J, Höckerstedt K, Hämäläinen $E$, Wähälä K. Dietary phytoestrogens and cancer: in vitro and in vivo studies. The Journal of Steroid Biochemistry and Molecular Biology. 1992;41(3-8):331-7. PMID: 1314077. Available from: 10.1016/0960-0760(92)90359-Q.

201. Chen AY, Chen YC. A review of the dietary flavonoid, kaempferol on human health and cancer chemoprevention. Food Chemistry. 2013;138(4):2099-107. PMID: 23497863. Available from: 10.1016/j.foodchem.2012.11.139.

202. Chen HJ, Lin CM, Lee CY, Shih NC, Peng SF, Tsuzuki M. Kaempferol suppresses cell metastasis via inhibition of the ERK-p38-JNK and AP-1 signaling pathways in U-2 OS human osteosarcoma cells. Oncology Reports. 2013;30(2):925-32. PMID: 23708932. Available from: 10.3892/or.2013.2490. 
203. Lee KM, Lee DE, Seo SK, Hwang MK, Heo YS, Lee KW. Phosphatidylinositol 3-kinase, a novel target molecule for the inhibitory effects of kaempferol on neoplastic cell transformation. Carcinogenesis. 2010;31(8):1338-43. PMID: 20530555. Available from: $10.1093 / \mathrm{carcin} / \mathrm{bgq} 102$.

204. Lenz KA, Pattison C, Ma H. Triclosan (TCS) and triclocarban (TCC) induce systemic toxic effects in a model organism the nematode Caenorhabditis elegans. Environmental Pollution. 2017;231 (Pt 1):462-70. PMID: 28837926. Available from: 10. 1016/j.envpol.2017.08.036.

205. Geens T, Neels H, Covaci A. Distribution of bisphenol-A, triclosan and n-nonylphenol in human adipose tissue, liver and brain. Chemosphere. 2012;87(7):796-802. PMID: 22277880. Available from: 10.1016/j.chemosphere.2012.01.002.

206. Wang LQ, Falany CN, James MO. Triclosan as a substrate and inhibitor of 3 '-phosphoadenosine 5 '-phosphosulfatesulfotransferase and UDP-glucuronosyl transferase in human liver fractions. Drug Metabolism and Disposition: the Biological Fate of Chemicals. 2004;32(10):1162-9. PMID: 15269185. Available from: 10.1124/dmd.104.000273.

207. Palmer RK, Hutchinson LM, Burpee BT, Tupper EJ, Pelletier JH, Kormendy Z. Antibacterial agent triclosan suppresses RBL-
$2 \mathrm{H} 3$ mast cell function. Toxicology and Applied Pharmacology. 2012;258(1):99-108. PMID: 22036726. Available from: 10.1016/j.taap.2011.10.012.

208. Higgins CP, Paesani ZJ, Chalew TE, Halden RU, Hundal LS. Persistence of triclocarban and triclosan in soils after land application of biosolids and bioaccumulation in Eisenia foetida. Environmental Toxicology and Chemistry. 2011;30(3):55663. PMID: 21128266. Available from: 10.1002/etc.416.

209. Xie X, Lu C, Wu M, Liang J, Ying Y, Liu K. Association between triclocarban and triclosan exposures and the risks of type 2 diabetes mellitus and impaired glucose tolerance in the National Health and Nutrition Examination Survey (NHANES 2013-2014). Environment International. 2020;136:105445. PMID: 31918332. Available from: 10.1016/j.envint.2019. 105445.

210. Huang $C L$, Abass OK, Yu CP. Triclosan: A review on systematic risk assessment and control from the perspective of substance flow analysis. The Science of the Total Environment. 2016;566-567:771-85. PMID: 27239720. Available from: $10.1016 /$ j.scitotenv.2016.05.002. 
Ready to submit your manuscript? Choose Biomedpress and benefit from:

- Fast, convenient online submission

- Through peer-review by experienced researchers

- Rapid publication on acceptance

- Free of charge (without publication fees)

Learn more http://www.biomedpress.org/journals/
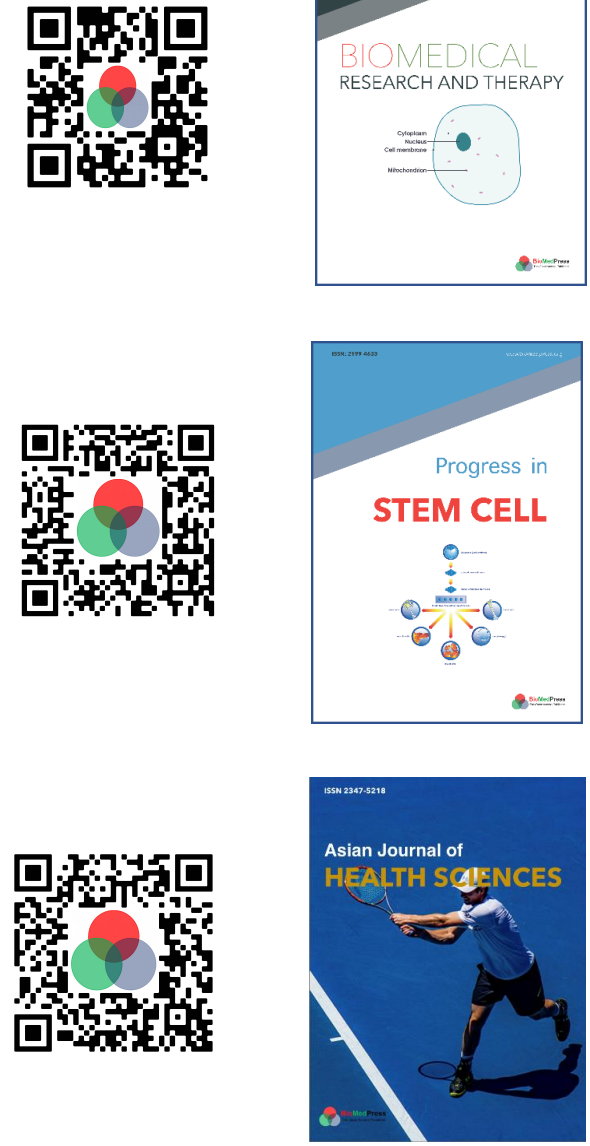

Asian Journal of Health Sciences

ISSN: 2347-5218

Indexed: Google Scholar

Acceptance Rate (2020): 72.89\%

Article Publishing Charge: Free

Submission to first editorial decision: 16.5 days

Biotechnological Research

ISSN: 2395-6763

Indexed: Google Scholar

Acceptance Rate (2020): $67.02 \%$

Article Publishing Charge: Free

Submission to first editorial decision: 28.5 days 